\title{
EXPERIMENTAL STUDY FOR THE BEHAVIOUR OF REINFORCED CONCRETE FLAT PLATES WITH DROP PARTS
}

\author{
Mohamed H. Matthana, Attia H. Bayomy, A.H. Abdel-Reheem, Ayman Mashaly \\ Structural Engineering Department, Faculty of Engineering, \\ EL-Mansoura University, Egypt
}

\begin{abstract}
The present paper presents an experimental investigation for the behaviour of flat plates provided with drop parts formed by partially decreasing both top and bottom fibers of the plate. The experimental study has been carried out on sixteen plate specimens one of them is kept flat without any drop parts to be the control case, while the other specimens are provided with drop parts having the same thickness of the plate, while they are located at different locations of the plate. The locations of the drops parts, considered in the present study, are the intersections of; two middle strips, two column strips, and one middle and one column strips. All plates had the same thickness and the same aspect ratio of 1.0, while the main parameters in the study were the dimensions of the drop part, the drop height and the location of the drop part. The plate specimens were supported on four concrete short columns and subjected to uniformly-distributed flexural loading where the cracking load, the overall cracking patterns in both sides after failure and the ultimate load are reported. The steel strains at selected locations and the deflection at chosen points are also measured. The study shows that the presence of drop parts in flat plates has a significant effect on the mode of failure of the plate while, this effect depends on the location and the size of the drop part. The deflections of the plate specimens at various measuring points and the strains developed in the reinforcing steel are also sensitive to the presence of such drop parts. The study brings out the surprising result that the load carrying capacity of plates with drop parts is relatively more than that of the flat plates without any drop parts.
\end{abstract}

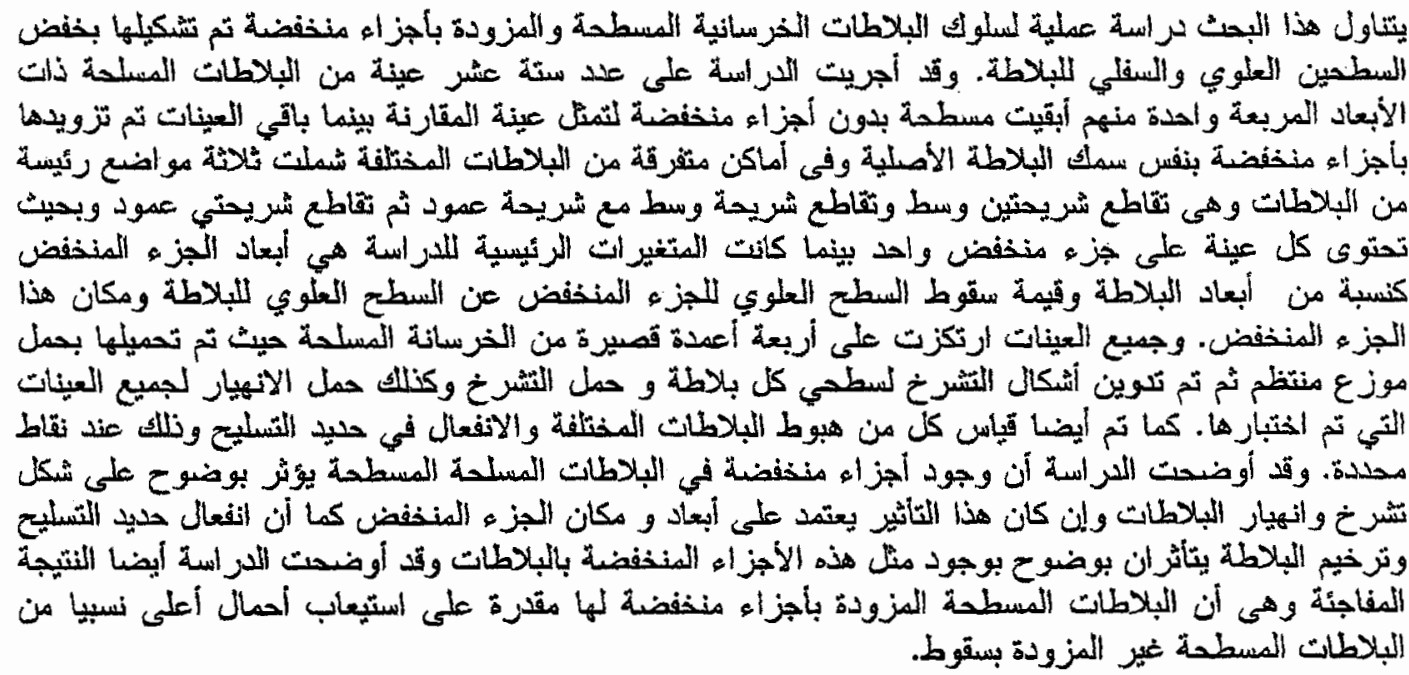

Keywords: Reinforced Concrete, Flat Slabs, Flat Plates, Plates \& Drop Parts.

\section{INTRODUCTION}

Flat slab systems refer to beamless slab systems with direct support at column-slab joint; hence loads are directly transferred from slabs to the supporting columns. Due to the absence of supporting beams, the columns tend to punch through the slab causing shear stresses in the slab and cracking around the columns. Among the methods used to prevent the slab failure, because of the punching shear, is to increase the slab thickness either partially around the columns or totally through the entire slab. The partial 
increase in the slab thickness around columns is usually defined as drop panel. If the drop panel is not used, the slab will be of uniform thickness and is referred as flat plate. In some cases, the top surface of the flat plate has to be partially decreased in some regions to meet some architectural requirements such as the existence of bath rooms or kitchens. In those cases, the architectural requirements may be fulfilled by decreasing the top surface and increasing the entire thickness of the plate or decreasing both top and bottom surfaces and keeping the minimum thickness required for the structural requirements. In the later case, the flat plate is then provided with drop parts. The presence of such drop part affects the behaviour of flat plates. Although the behaviour of flat slabs and flat plates has met a lot of interest in the literature, very few studies have been carried out regarding the case of flat plate with drop parts. Ghali and Megally, (1999) presented a design procedure for the connections of columns to flat plates to insure safety against punching failure. El-Salakawy et. Al., (1999), studied the behaviour of flat plate edge connections with an opening in the vicinity of the column through six full-scale plate specimens. Carl Erik Broms, (2000), proposed a design concept to eliminate the punching failure mode of flat plates. Abd El Baki, O. F., (2002), studied the behaviour of flat plates with a drop part at the middle zone. $\mathrm{He}$ derived an equation to estimate the deflection of such plates and compared the results of this equation with a finite element analysis. In the present paper an attempt has been made to study the effect of drop parts on the behaviour of flat plates. An experimental study has been carried out on sixteen plate specimens one of them is kept flat without any drop parts to be the control case while, the other specimens are provided with drop parts having the same thickness of the plate while, they are located at different locations of the plate. The locations of the drops parts, considered in the present study, are the intersections of; two middle strips, two column strips, and one middle and one column strips. All plates had the same thickness and the same aspect ratio of 1.0 , while the main parameters in the study were the dimensions of the drop part, the drop height and the location of the drop part. The plate specimens were supported on four concrete short columns located at the four corners of the plate. The plates are subjected to uniformly-distributed flexural loading where the cracking loads, the overall cracking patterns in both sides after failure and the ultimate load are reported. The strains of the reinforcing steel and the plate deflections are also measured at selected points.

\section{DETAILS OF THE EXPERIMENTAL STUDY}

\subsection{Details of the Test Specimens}

The test specimens, used in the present experimental study, include sixteen plate specimens. One of the plate specimens is a flat plate without any drop parts to be the control specimen, while the other number of plate specimens is divided into three groups. The plate specimens in the first group are provided with drop parts located at the intersection of two middle (field) strips; group (M-M), while the specimens of the second group are provided with drop parts at the intersection of one middle and one column strips; group (M-C). In the last group of plate specimens, the drop parts are located at the intersection of two column strips; group (C-C). The aspect ratio of all plate specimens is kept constant at 1.0. All specimens have the same dimensions of $125 \times 125 \mathrm{~cm}^{2}$ and 5.0 $\mathrm{cm}$ thickness. Each plate specimen is provided with reinforcing steel wires with $3.4 \mathrm{~mm}$ diameter arranged at a spacing of $5.0 \mathrm{~cm}$ and located at suitable zones according to the plate configurations. The plates are supported at four reinforced concrete columns located at the four corners of each plate. Each column has a square cross section with the dimensions of $10 \times 10 \mathrm{~cm}^{2}$ and a clear height of 25 $\mathrm{cm}$ while the column is provided with four longitudinal bars each of $8.0 \mathrm{~mm}$ diameter and stirrups with $3.4 \mathrm{~mm}$ diameter arranged at a spacing of $5.0 \mathrm{~cm}$. The configurations of the plate specimens are changed to meet the requirements of the various parameters of the present study. As the parametric study included the effect of drop dimensions, some of the plate specimens are provided with drop parts varied in its dimensions from 0.0 ; in the case of flat plate, to the full width of the field strip. The height of the drop part has, also, been changed in some of the plate specimens. The change varied between 0.0 to twice the value of the plate thickness; $10.0 \mathrm{~cm}$. The details of various groups of plate specimens are given in Table (1), while Figures (1) and (2) show the configurations of the tested plate specimens.

\subsection{Materials}

Normal strength concrete with an average compressive strength of $35 \mathrm{MPa}\left(350 \mathrm{~kg} / \mathrm{cm}^{2}\right)$ is used for all plate specimens. Fine aggregate from natural sand is used. The used sand was clean and free from impurities, silt, and clay. Coarse aggregate from natural gravel with a nominal maximum size of 9.51 $\mathrm{mm}(3 / 8 \mathrm{inch})$ is used. Gravel batches employed was clean and free from injurious matter. The same ordinary Portland cement is used along with potable water in all specimens. The compressive strength of the used concrete is measured through $15 \times 15 \times 15 \mathrm{~cm}^{3}$ concrete cubes where an average value of $350 \mathrm{~kg} / \mathrm{cm}^{2}$ is obtained. Cylindrical concrete specimens with 15 $\mathrm{cm}$ diameter and $30 \mathrm{~cm}$ height are used for the measurements of the splitting tensile strength and the modulus of elasticity. The tested concrete cylinders have shown an average value for the tensile strength of $28.9 \mathrm{~kg} / \mathrm{cm}^{2}$ while the average value of the modulus of elasticity is found to be $193746 \mathrm{~kg} / \mathrm{cm}^{2}$. 
Mechanical mixing and mechanical compacting in steel moulds using a table vibrator is maintained for all mixes used for the determination of the properties of used concrete. Wooden forms with dimensions of $125 \times 125 \mathrm{~cm}^{2}$ are used for casting plate specimens. At the beginning of the mixing process of concrete, the constituents were mixed in its dry state to insure the uniformity of the mix then, mixing water was added gradually and the contents were mixed in a vertical axis drum mixer for a period of two minutes. Both Mixing and casting processes of concrete are carried out at room temperature $(24 \pm 5 \mathrm{C})$. All moulds are removed after 24 hours from casting and the concrete specimens are kept in water for $\mathbf{2 8}$ days for curing while, the plate specimens are kept under damp jute bags for 28 days for curing. The Egyptian code and standards [3-8] are followed. The details of concrete mix are summarized in Table (2). Mild steel wires with $3.4 \mathrm{~mm}$ diameter are used in the reinforcement of all plate specimens. Three wire specimens are subjected to tensile tests to evaluate the yield strength, the ultimate strength and the elongation percent. The results are presented in Table (3). The tensile test of the steel reinforcement was carried out according to the Egyptian Standards .E.C.C.S (2032001).

\subsection{Test Procedure}

All plate specimens are tested in a loading frame under uniformly distributed compressive loading. A concentrated load from a 60 ton capacity hydraulic jack was transferred to the plate specimen through a grid system of steel beams. Wooden blocks of $10 \times 10 \times 5 \mathrm{~cm} 3$ are used to transfer the load from the grid of steel beams to the top surface of the plate specimen as a distributed load. Figure (3) shows the configurations of the loading system while, the photo of the complete experimental set-up is shown in Plate (1). The deflections of the tested plate specimens are monitored through two mechanical dial gauges each of $0.01 \mathrm{~mm}$ accuracy and a total capacity of 50.0 $\mathrm{mm}$. The positions of dial gauges are shown schematically in Fig. (1). The strains in reinforcing steel are measured using electrical resistance strain gauges. The gauges are installed on the reinforcing steel using an adhesive material. After soldering the lead wires to the strain gauge, the whole connection was coated to protect them against humidity and temperature. Later another vinyl mastic coat was overlapped the entire junction to guard against water leakage and mechanical damage during casting. The locations of strain gauges are shown in Fig. (1). At the beginning of loading, small fractions of the expected failure loads of various plate specimens were applied slowly and then removed in order to exercise the strain instruments. Load is then applied in small increments and all the deflections and the strain readings are manually recorded at the end of each load increment. The initiation and propagation of bottom cracks were marked and the mode of failure was noted after final collapse. The initiation of cracks at the top surface of the plate specimens could not be accurately marked because of the arrangements of the loading system at the top surface of the plate while, the cracking pattern of the top surface was reported after failure.

\section{RESULTS, DISCUSSIONS, AND MAJOR OBSERVATIONS}

Cracking Patterns, Cracking Loads, and Ultimate Loads of Various Plate Specimens

The photos of Plate (2) show the cracking patterns of both bottom and top surfaces of various groups of plate specimens. Table (4) summarizes the experimental results of the values of both cracking and ultimate loads while, figure (4) shows a histogram for both cracking and ultimate loads of various plate specimens. As mentioned above, the initiation of cracks at various regions of the top surface of the plate could not be accurately marked because of the arrangements of the loading system at the top surface of the plate but, on the other hand, the initiation and propagation of cracks at the bottom surface of the plate was marked for all specimens. As a general notice, the cracking patterns of various plate specimens show extensive cracking on the bottom surface of plates while, the cracks on the top surfaces are concentrated around the supporting columns. This agrees with the cracking patterns expected for flat plates. For the control plate specimen; S0, the plate developed its first crack in the form of hair cracks at the top surface of the plate around the supporting columns. These cracks did not much propagate while it is rapidly followed by another set of cracks in the bottom surface at a load of 2.6 ton which is about $41 \%$ of the plate ultimate load. The bottom cracks started, nearly, at the center of the plate and propagated towards the middle of the column strips in the four edges (Plate 2-a) till the failure of plate at a load of 6.3 ton. For plates having drop parts at the intersection of two middle strips; (group M-M), similar cracking patterns are found for the group specimens regardless the different factors; (1) the drop dimensions and (2) the drop height; (Plate 2, b-j). For all cases of the M-M group, the cracks observed at the bottom surface of the plate at the region between the corners of the drop part and the supporting column in the shape of diagonal cracks perpendicular to the line connecting the drop corner and the neighboring column. With the increase in the applied load, the cracks propagated and new sets of cracks parallel to the earlier ones occurred. With a further increase in the applied load, the developed cracks branched out and moved towards the edges between supports in the two directions and this continued till the complete failure 
of the plate. The comparison between both cracking and ultimate loads of various plate specimens, held in Table (4), shows that the cracking load of the plate is relatively enhanced when the plate is provided with a drop part with various drop heights. Table (4) shows also the superiority of the ultimate loads when the plate is provided with drop parts. This superiority becomes clearer with an increase in the size of the drop part. This may be understood as an effect of the increase in the plate inertia due to the drop part. The increase in the plate inertia reduces the stresses developed in the plate which in turn increases the load carrying capacity of the plate. In plate specimens (M-M11) and (M-M21) where the plates are provided with very small drop parts; $(\alpha=0.125 \&$ $\mathrm{d}=5.0 \& 7.5 \mathrm{~cm}$ respectively), the plates show a reverse behaviour where the existence of the drop part leads to the reduction in both cracking and ultimate loads. This may be explained as: for this very small value of $\alpha$, the drop part acts as a hole causing concentration of stresses. Plate specimen (MM31) with the same small value of the drop ratio $(\alpha=0.125)$ and relatively higher value of the drop height; $d=10.0 \mathrm{~cm}$, shows a better situation as its cracking and ultimate loads show values which are about $96 \%$ and $100 \%$, respectively, of the corresponding values of the control specimen.

When the plate is provided with drop part located in the area common to the intersection of two column strips (group $\mathrm{C}-\mathrm{C}$ ), the same observation of the concentration of cracks in the upper surface around columns and the extensive cracking on the bottom surface of plates, as the case of M-M group, is also noticed (Plate 2, $k-m$ ). For the tested specimens, bottom flexural cracks were initiated near the center of the plate and gradually propagated towards the middle of the edges between supports in the two directions. Another set of cracks initiated in the bottom surface of the plate; perpendicular to the line connecting two diagonal columns, and propagated in the region around columns. Plate $(2-k)$ shows the cracking pattern of plate specimen (C-C1) where the plate is provided with a drop part with $\alpha_{x}=0.125, \alpha_{y}$ $=0.17 \&$ drop height $=7.5 \mathrm{~cm}$. It is noticed that the drop part is relatively small to the extent that, it acts with the edge colnun as a supporting zone. Plates (2L) \& (2-m) show the plate specimens (C-C2) and (C$\mathrm{C} 3)$ where, the plate specimens are provided with drop parts with relatively larger dimensions. The specimens fail by the propagation of the flexural cracks initiated in the bottom regions around columns perpendicular to the line connecting two diagonal columns. Table (4) shows that, the existence of drop part relatively enhances both cracking and ultimate loads of the plate especially with the increase in the drop dimensions.
For plates having drop part located at the intersection of one middle strip and one column strip; (group MC), the bottom cracks were observed, nearly, at the center of the plate. The cracks branched out and moved towards the edges between supports in the two directions and around the drop part. Another set of diagonal cracks occurred in the bottom region around columns. Both middle and diagonal cracks propagated with the increase in the applied load till the plate failed by the propagation of the middle cracks. Plate (2-n) shows a photo for the plate specimen (M-C1) where the plate is provided with a drop part with $\alpha_{x}=0.125, \alpha_{y}=0.25$. As shown in the photo, the main crack continues till it divides the plate into approximately two equal parts one of then contains the drop part. When the size of the drop part is further increased; plates (M-C2) and (M-C3), the same cracking pattern of plate $(\mathrm{M}-\mathrm{Cl})$ was observed while the load carrying capacity of the plate was relatively enhanced. This may be explained as, the column strip, in this case, including the drop part acts as a wide beam attracts more loads and more moments because of its relatively higher stiffness. This, what is called, wide beam was cracked at center of the specimen perpendicular to the beam axis. As shown in Table (4), both the cracking and the ultimate loads of the plate have been relatively enhanced with the existence of the drop part.

Load-Deflection Response of Various Specimens

Figures (5) \& (6) show the load deflection relationship of $M-M$ group of the tested plate specimens; which are provided with drop parts at the intersection of two field strips, at the pints of measurements (points $\mathrm{P} 1 \& \mathrm{P} 2$ ). The drop parts of this group have various drop dimensions and various drop heights. As shown in Figure (5), the plate specimens provided with drop parts; (M-M group), show lower values of deflections at the plate centre (point P1) than the values of the control specimen of solid plate without any drop part. This happened for all specimens of the group except for specimens $M$ M11, M-M21, \& M-M31, which are provided with drop parts with very small dimensions; $\alpha_{X}=\alpha_{Y}=$ 0.125 . This may be understood as an effect of the increase in the stiffness of plates provided with drop parts with relatively larger dimensions. On the other hand, the plates with relatively small drop part act as plates with central hole and this in turn reduces the plate stiffness and increases the plate deflection. The figure also shows plates M-M13, M-M23, \& M-M33 which have the largest dimensions of the drop part where all the three plates show the least values of central deflection. The central deflections of such plates get reduced with the increase in the drop height; $d$. This means that, the height of the drop part plays a significant rule in the plate deflection; as the deflections of various plates reduce with an increase in the drop height. This happened for all plates of the 
M-M group except for plates with $\alpha=0.125$. In Figure (6), the variation in the deflection of point $\mathrm{P} 2$; which lies at the middle of the plate edge, is plotted. The existence of drop parts increases the deflection of the plate specimen at point P2; except for the case when the drop part has relatively larger dimensions $\left(\alpha_{x}=\right.$ $\left.\alpha_{Y}=0.5\right)$ especially with an increase in the drop height.

Figures (7) \& (8) show the effect of the drop ratio $\left(\alpha_{\mathrm{X}} \& \alpha_{\mathrm{Y}}\right)$ on the deflection of the M-M group of plate specimens at the selected points P1 \& P2 for two cases of loading; the first case before cracking at a total load of 1.714 ton while, the second at a load of 4.571 ton after cracking. As shown in figures, the deflections of plates at the two selected points of measurements get reduced with the increase in the drop ratio. This happened for all cases of the drop height; $d$. The figures also show that, for all cases of the drop ratio, the drop height plays an important rule in the values of deflection. The deflection at various points reduces with the increase in the drop height. In Figures (9-12), the relationships between the drop ratio and the deflection factor, which represents the ratio between the deflection of various plate specimens and the deflection of the control plate at the corresponding measuring points, are plotted. Again, the reduction in the plate deflection with the increase in both the drop height and the drop ratio is clearly noticed. Figures (13) to (16) show the variations in the deflection factor with the drop height for various cases of the drop ratio $\left(\alpha_{X}=\alpha_{Y}=\right.$ $\alpha)$ for the two cases of loading; before and after cracking. The figures enhance the understanding that, the deflection of various plate specimens gets reduced with an increase in any of the drop height or the drop ratio. This happens for all loading stages.

Figures (17) \& (18) show the load deflection relationships of $\mathrm{C}-\mathrm{C}$ group of plate specimens; which are provided with drop parts at the intersections of column strips, at the two selected pints P1 \& P2. As shown in Figure (17), the deflection of various plate specimens of the group is, nearly, equal to the deflection of the control plate specimen; S0, except for plate specimen C-C3 which has a drop part with relatively large dimensions $\left(\alpha_{X}=\alpha_{Y}=0.25 \&\right.$ $X=Y=0.0$ ). The large dimensions of the drop part, which nearly coincide with the dimensions of the column strip of the plate, make the plate specimen develops higher stiffness and leads to smaller values of the central deflection than the other specimens of the same group. In Figure (18) a similar behaviour is observed where, all the plate specimens develop lower values of the deflection at point P2 than the control specimen. The increase in the drop dimensions leads to the reduction in the plate deflection. Plate Specimen C-C3 also shows the least values of the measured deflection at point $P 2$ while the other two specimens of the group; Plates C-C1 \& $\mathrm{C}-\mathrm{C} 2$, show values of deflections which are relatively closer to the control specimen. Figure (19) shows the variation in the deflection of various plate specimens of the $\mathrm{C}-\mathrm{C}$ group with the drop ratio for two loading stages; before and after cracking (loads 1.714 ton and 4.571 ton). The figure shows the reduction in the measured deflection at both points in cases of large drop dimensions while, the specimens with relatively small drop dimensions show deflections with very close values to those of the control plate specimen. In Figures (20) \& (21) the effect of the drop width ratio $\left(\alpha_{\mathrm{X}}\right)$ on the deflection factor is plotted for group C-C at the two measuring points P1 \& P2.

The load deflection relationships of plate specimens provided with drop parts at the intersection of middle and column strips; M-C group, at the two selected pints of measurements; P1 \& P2, are plotted in Figures (22) \& (23). Again, the reduction in the deflection of plates with drop part than the control plate becomes very clear. The reduction in the plate deflection increases with the increase in the drop dimensions. The figures also show that, the existence of drop part affects the deflection of the plate specimen at point P2 more that its effect on the central point P1. Figure (24) shows the relationship between the deflection of the plate specimen at the two measuring points; $\mathrm{Pl} \& \mathrm{P}$, and the drop ratio at two loading stages; before and after cracking. The reduction in the deflection with the increase in the drop ratio is noticed for the two loading stages. The effect of the drop ratio is again plotted as a relationship with the deflection factor in Figures (25) and (26). The same observation of the reduction in the deflection factor with the increase in the drop ratio is noticed for the two loading stages. Table (5) summarizes the values of the measured deflections of various plate specimens at the two measuring points at two loading stages; before and after cracking. Strain in the Reinforcing Steel of Various Plates The variations in strains in the reinforcing steel wires at the selected points of measurements; G1, G2, and G3, are shown in Figures (27 to 38). Figures (27) to (29) show the variation in steel strains for all the plate specimens at $\mathrm{G} 1, \mathrm{G} 2$, and $\mathrm{G} 3$ respectively. As a general notice, each of the considered factors; the drop position, the drop dimensions, and the drop height plays some rule in the strains developed in the reinforcing steel wires. The considered factors affect the values of strains at gauges G1 \& G3; which are fixed to the reinforcing steel at the bottom fiber of the plate center and the top fiber of the plate corner, respectively, while, it has an effect on both the magnitude and the direction of the strains developed in steel at the top fiber of the drop corner; gauge G2. This happened for the plate specimens provided with drop parts at the intersection of two middle strips; group $\mathrm{M}-\mathrm{M}$. In group $\mathrm{M}-\mathrm{M}$, the strains at G2 vary 
from tension to compression with a change in any of the drop size or the drop height while, in the other two groups; C-C and $\mathrm{M}-\mathrm{C}$, the direction of strain at G2 has not been changed. In Figures (30) to (32), the same relations are plotted for the plate specimens provided with drop parts at the intersection of two middle strips; $M-M$ group, only. The results show that, the increase in both the drop dimensions and the drop height, relatively, reduces the values of strains in both bottom and top reinforcing steel wires. At gauge $\mathrm{G} 2$, the strains developed in steel are relatively sensitive to the change in any of the drop size or drop height. The measured strains show changes in its directions from tension to compression with a change in any of the drop size or the drop height. Figures (33) to (35) show the variation in the steel strains for the $\mathrm{C}-\mathrm{C}$ group of plate specimens which; are provided with drop parts at the intersection of two column strips. The same observation of the reduction in the steel strains with an increase in the drop dimensions is noticed for the measuring point G1 \& G3 while point $\mathrm{G} 2$ has shown a reverse relation as the strains increased with the increase in the drop size. This may be understood as an effect for the change in both values and directions of strains at point $\mathrm{G} 2$ as an effect of the change in the drop size; especially that, for the C-C group both the position and the size of the drop part have been changed. The variations in steel strains of the plate specimens provided with drop parts at the intersection of one middle strip and one column strip; $\mathrm{M}-\mathrm{C}$ group, are shown, for the three measuring points, in Figures (36) to (38). Again the same observation of the reduction in strains with an increase in the drop dimensions is noticed.

\section{CONCLUSIONS}

Based on the present experimental study, the following conclusions may be drawn:

1. The presence of drop parts has a significant effect on the modes of failure of flat plates. The effect depends on the location and the size of the drop part. For all the considered plate specimens, the plate shows extensive flexural cracking at the top surface in the four corner regions around columns and at the bottom surface. For the control plate without drop parts, the bottom cracks started, nearly, at the center of the plate and propagated towards the middle of the column strips in the four edges till the failure of plate. For plates having drop parts at the intersection of two middle strips, the cracks observed at the bottom surface of the plate at the region between the corners of the drop part and the supporting column; in the shape of diagonal cracks perpendicular to the line connecting the drop corner and the neighboring column. With the increase in the applied load, the cracks propagated and new sets of cracks parallel to the earlier ones occurred. With a further increase in the applied load, the developed cracks branched out and moved towards the edges between supports in the two directions and this continued till the complete failure of the plate. When the plate is provided with a drop part at the intersection of two column strips, the bottom flexural cracks were initiated near the center of the plate and gradually propagated towards the middle of the edges between supports in the two directions. Another set of cracks initiated in the bottom surface of the plate perpendicular to the line connecting two diagonal columns and propagated in the region around columns. For plates having drop part located at the intersection of one middle strip and one column strip, the bottom cracks were observed nearly at the center of the plate. The cracks branched out and moved towards the edges between supports in the two directions and around the drop part. Another set of diagonal cracks occurred in the bottom region around columns. Both middle and diagonal cracks propagated with the increase in the applied load till the plate failed by the propagation of the middle cracks.

2. In flat plates with drop parts, the drop dimensions have some effect on the modes of failure while the drop height does not affect the modes of failure of the plate. For plates provided with drop parts at the intersection of two middle strips, the cracks observed at the bottom surface of the plate at the region between the corners of the drop part and the supporting column in the shape of diagonal cracks perpendicular to the line connecting the drop corner and the neighboring column. The cracks propagated towards the edges between supports in the two directions till the complete failure of the plate while, none of those cracks crossed the bottom region of the drop part. This cracking pattern is observed in various plates of the group with various drop dimensions and drop heights. The only difference between one cracking pattern and another one in the group is the size of the area of the cracking region of the bottom surface and this varied with the variation in the drop dimension while the drop height did show any effect. When the plates are provided with drop parts located at the intersection of two column strips, bottom flexural cracks were initiated near the center of the plate and gradually propagated towards the middle of the edges between supports in the two directions. Another set of cracks initiated in the bottom surface of the plate perpendicular to the line connecting two diagonal columns and propagated in the region around columns. In the case of plate specimen (C-C1); where the plate is provided with a drop 
part with $\alpha_{x}=0.125, \alpha_{y}=0.17 \&$ drop height $=$ $7.5 \mathrm{~cm}$, it is noticed that the drop part is relatively small to the extent that it acts with the edge column as a supporting zone. When the drop dimensions are increased in plate specimens (CC2) with $\alpha_{x}=0.17, \alpha_{y}=0.25 \&$ drop height $=7.5$ $\mathrm{cm}$, the plate specimens fail by the propagation of the flexural cracks initiated in the bottom regions around columns perpendicular to the line connecting two diagonal columns. With a further increase in the drop dimensions; plate (C-C3) with $\alpha_{x}=0.25, \alpha_{y}=0.25 \&$ drop height $=7.5 \mathrm{~cm}$, the bottom flexural cracks initiated in the bottom regions around columns perpendicular to the line connecting two diagonal columns and crossed the bottom surface of the drop part. For plates having drop parts located at the intersection of one middle strip and one column strip, the bottom cracks were observed nearly at the center of the plate. The cracks branched out and moved towards the edges between supports in the two directions and around the drop part. Another set of diagonal cracks occurred in the bottom region around columns. Both middle and diagonal cracks propagated with the increase in the applied load till the plate failed by the propagation of the middle cracks. This cracking pattern is observed in various plates of the group with various drop dimensions. The only difference between one cracking pattern and another one in the group is the size of the area of the cracking region of the bottom surface and this varied with the variation in the drop dimensions.

3. The presence of drop parts affects both cracking and ultimate loads of the flat plates. The significance of this effect depends on the size as well as the position of the drop part in the considered plate. The experimental results of the present study show that, both the cracking and ultimate loads of flat plates with drop parts are higher than the corresponding values of the control plate without drop part. This happened for all plates except for the case when the plate is provided with a drop part at the intersection of two middle strips with $\alpha=0.125$ this may be explained as the drop, in this case, acts as a hole. In this specimen the cracking load ranged from $88 \%$ to $96 \%$ and the ultimate load ranged from $91 \%$ to $100 \%$ of the corresponding values of the control plate when the drop height ranged from 5.0 to $10.0 \mathrm{~cm}$.

4. The dimensions of drop parts affect both cracking and ultimate loads of flat plates provided with drop parts. The significance of this effect is very sensitive to the position of the drop part. In the case of plates provided with drop parts at the intersection of two middle strips, both cracking and ultimate loads significantly increase with an increase in the drop dimensions while, in the other two cases of plates; with drop parts at the intersections of one columns trip and one middle strip or two column strips, the increase in both cracking and ultimate loads due to the increase in the drop ratio is relatively less. For the tested plate specimens with drop parts at the intersection of two middle strips and a drop height of $10.0 \mathrm{~cm}$, the cracking load increased from $96 \%$ to $131 \%$ and the ultimate load increased from $100 \%$ to $127 \%$ of the corresponding values of the control specimen when the drop ratio increased from 0.125 to 0.5 . When the plate is provided with a drop part at the intersection of two column strips, the cracking load increased from $100 \%$ to $106 \%$ and the ultimate load increase from $100 \%$ to $111 \%$ of the corresponding values of the control plate when the drop ratios increased from $\alpha_{x}=$ $0.125 \& \alpha_{y}=0.17$ to $\alpha_{x}=0.25 \& \alpha_{y}=0.25$. For Plates with drop parts at the intersection of one middle strip and one column strip, the cracking load increases from $100 \%$ to $106 \%$ and the ultimate loads increases from 100 to $109 \%$, only, of the corresponding values of the control plate duo to the increase in the drop ratios from $\alpha_{\mathrm{x}}=$ $0.125 \& \alpha_{y}=0.25$ to $\alpha_{x}=0.25 \& \alpha_{y}=0.50$.

5. The height of the drop part significantly affects both the cracking and the ultimate loads of flat plates provided with drop parts at the intersection of two middle strips. For the considered plate specimens, the cracking load ranged from $88 \%$ to $110 \%$ and the ultimate load ranged from $91 \%$ to $118 \%$ of the corresponding values of the control plate when the plate is provided with a drop part with a height of $5.0 \mathrm{~cm}$ only. When the drop height is increased to $7.50 \mathrm{~cm}$, the cracking load ranged from $88 \%$ to $123 \%$ and the ultimate load ranged from $91 \%$ to $124 \%$ of the corresponding values of control plate. With a further increase in the drop height to be $10.0 \mathrm{~cm}$, the cracking load ranged from $96 \%$ to $131 \%$ and the ultimate load ranged from $100 \%$ to $127 \%$ of values of the control plate.

6. The size of drop part affects the deflections of flat plates at various points. For all cases of plate specimens, the deflections significantly reduce with an increase in the drop dimensions. This happened for the two points of measurements. The results also show that, the drop height plays a similar rule on the values of various deflections while, its effect is lower than that of the drop dimensions. The deflections of the plate slightly reduce with an increase in the drop height.

7. The presence of drop part affects the strains developed in the reinforcing steel wires. For all 
cases of plate specimens, the drop position and drop size affects the values of strains at the strain gauges fixed to the reinforcing steel at the bottom fiber of the plate center and the top fiber of the plate corner. On the other hand, the drop size has an effect on both of the magnitude and the direction of the strains developed in steel at the top fiber of the drop corner of plate specimens provided with drop parts at the intersection of two middle strips. In such plate specimens, the strains at the corner of the drop part vary from tension to compression with a change in any of the drop size or the drop height, while in the other groups, the direction of strains at the drop corner has not been changed. In general, the values of the developed strains relatively reduce with an increase in the drop size.

\section{REFERENCES}

[1] Abd El-Baki O. F., " Behavior and Analysis of Flat Plates with drop part", M. Sc. thesis, Faculty of Engineering, El- Mansoura University, ElMansoura, Egypt, 2002.

[2] Carl Erik Broms., "Elimination of Punching Failure Mode," ACI Journal, Vol.97, No.1, January-February 2000, pp.97-S11.

[3] Egyptian Standard, ES:1109-1971, "Concrete Aggregates from Natural Sources", Egyptian Organization for Standardization and Quality Control, Egypt, 1971.
[4] Egyptian Standard, ES: 1658-1993, "Testing Concrete", Egyptian Organization for Standardization and Quality Control, Egypt, 1993.

[5] Egyptian Standard, ES: 2421-1993, "CementPhysical and Mechanical Testing", Egyptian Organization for Standardization and Quality Control, Egypt, 1993.

[6] Egyptian Code for Design and Construction of Reinforced Concrete Structures, Ministry of Housing and Urbanization, (EGCP-1995), Fourth Edition, Cairo, Egypt, 1998.

[7] Egyptian Code for Design and Construction of Reinforced Concrete Structures, Ministry of Housing and Urbanization, (ECCS 203-2001), Second Revision, Eighth Edition, Cairo, Egypt, 2001.

[8] Egyptian Code for Design and Construction of Reinforced Concrete Structures, Ministry of Housing and Urbanization, (ECCS 203-2003), Second Revision, Eighth Edition, Cairo, Egypt, 2003.

[9] EI-Salakawy, E. F., Polak, M. A. and Soliman, M. H., "Reinforced Concrete Slab-Column Edge Connections with Openings", ACI Journal, Vol.97, No.3, January-February 1999, pp.79-S9.

[10] Ghali, A. and Megally, S., "Design for Punching Shear Strength with ACI 318-95", ACI Journal, Vol. 96, No.4, July-August 1999, pp. 539-560.

Table 1 Details of the Tested Plate Specimens

\begin{tabular}{|c|c|c|c|c|c|c|c|c|c|c|}
\hline \multirow{2}{*}{$\begin{array}{l}\text { Slab } \\
\text { Model }\end{array}$} & \multirow{2}{*}{$\begin{array}{c}\mathbf{L} \\
(\mathrm{cm})\end{array}$} & \multicolumn{2}{|c|}{ Drop Dimensions } & \multicolumn{2}{|c|}{ Drop Ratio } & \multicolumn{2}{|c|}{ Position of Drop Part } & \multirow{2}{*}{$\begin{array}{c}\text { Drop } \\
\text { Height } \\
\text { d (cm) }\end{array}$} & \multirow{2}{*}{$\begin{array}{c}\text { Drop at the } \\
\text { Intersection of }\end{array}$} & \multirow[b]{2}{*}{ Reinforcement } \\
\hline & & a (cm) & b (cm) & $\alpha_{x}=a / L$ & $\alpha_{Y}=b / L$ & $X(\mathrm{~cm})$ & $\mathbf{Y}(\mathbf{c m})$ & & & \\
\hline So & 125 & 000 & 000 & 0.000 & 0.000 & 0.000 & 000 & 0.00 & No drop & 1ф3.4mm@ \\
\hline M-M11) & 125 & 15.625 & 625 & 125 & 0.125 & 70 & .70 & 00 & 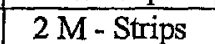 & \\
\hline S(M-M12) & 125 & 31.250 & 31.250 & 0.250 & 0.250 & .90 & 46.90 & 5.00 & $2 \mathrm{M}$ & $1 \phi 3$ \\
\hline & 125 & 62.500 & 62.500 & 0.500 & 0.500 & 31.25 & 31.25 & 5.00 & $2 \mathrm{M}$ - Strips & \\
\hline$S(\mathbb{M}$ & 125 & & & 0.125 & 0.125 & & & & trips & -1 \\
\hline & 125 & 31.250 & .2 & 0.250 & 0. & 5.90 & & 7. & & 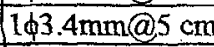 \\
\hline S(M-M23) & 125 & 62.500 & 62.500 & 0.500 & 0.500 & 1.23 & 25 & 7.50 & trips & \\
\hline & 125 & 15.625 & 15.625 & 0.125 & 0.125 & 54.70 & 54.70 & 10.0 & Strips & $1 \phi 3$. \\
\hline & 125 & & 50 & 0.250 & 0.250 & 90 & 90 & 10.0 & Strips & $1 \phi 3$. \\
\hline$\overline{S O M}$ & 125 & 0 & & 00 & 0.500 & & & 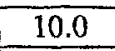 & trips & $\mathrm{m} @ 5 \mathrm{~cm}$ \\
\hline $\mathrm{S}(\mathrm{M}-\mathrm{C} 1)$ & 125 & 15.625 & 31.250 & 0.125 & 0.250 & 15.00 & 46.90 & 7.50 & ps & $1 \phi$ \\
\hline $\mathrm{S}(\mathrm{M}-\mathrm{C} 2)$ & 125 & 21.250 & 46.875 & 170 & 0.375 & 0.00 & 39.05 & 7.50 & trips & $11 \mathrm{~d}$ \\
\hline S (M-C3) & 125 & 31.250 & 62.500 & 0.250 & 0.500 & 0.000 & 31.25 & 7.50 & M -C Strips & 1ф3.4mm@5 \\
\hline $\mathrm{S}(\mathrm{C}-\mathrm{Cl})$ & 125 & 15.625 & 21.250 & 0.125 & 0.170 & 15.00 & 10.00 & 7.50 & 2C-Strips & 1ф3.4mm@5 cm \\
\hline $\mathrm{S}(\mathrm{C}-\mathrm{C} 2)$ & 125 & 21.250 & 31.250 & 0.170 & 0.250 & 10.00 & 0.000 & 7.50 & 2C-Strips & $1 \phi 3.4 \mathrm{~mm} @ 5 \mathrm{~cm}$ \\
\hline $\mathrm{S}(\mathrm{C}-\mathrm{C} 3)$ & 125 & 31.250 & 31.250 & 0.250 & 0.250 & 0.000 & 0.000 & 7.50 & 2C-Strips & $1 \phi 3.4 \mathrm{~mm} @ 5$ \\
\hline
\end{tabular}

$M=$ Middle Strip \& $C=$ Column Strip 
Mohamed H. Matthana, Attia H. Bayomy,A.H. Abdel-Reheem,Ayman Mashaly, "Experimental Study... "

Table 2 Mix Proportions for the Used Concrete

\begin{tabular}{|l|c|c|c|c|c|}
\hline & Cement & Sand & Gravel & Water & Water/Cement Ratio \\
\hline Material Weights $\left(\mathrm{kg} / \mathrm{m}^{3}\right)$ & 400 & 650 & 1150 & 200 & 0.50 \\
\hline
\end{tabular}

Table 3 Test Results of the Used Reinforcing Mild Steel.

\begin{tabular}{||c|c|c|c|c|c|c|}
\hline \multirow{2}{*}{$\begin{array}{c}\text { Diameter } \\
(\mathrm{mm})\end{array}$} & \multicolumn{2}{|c|}{ Average Strength $\left(\mathrm{Kg} / \mathrm{cm}^{2}\right)$} & \multicolumn{2}{|c|}{ Tensile Strength $\left(\mathrm{Kg} / \mathrm{cm}^{2}\right)$} & \multicolumn{2}{|c|}{ Elongation \% } \\
\cline { 2 - 7 } & Result & Code Limit & Result & Code Limit & Result & Code Limit \\
\hline 3.4 & 2550 & 2400 & 3700 & 3500 & $22 \%$ & $20 \%$ \\
\hline
\end{tabular}

Table 4 Experimental Values of Cracking and Ultimate Loads of Various Plate Specimens

\begin{tabular}{|c|c|c|c|c|c|c|c|c|c|c|}
\hline \multirow{2}{*}{ Model } & \multicolumn{2}{|c|}{ Drop Ratio } & \multirow{2}{*}{$\begin{array}{l}\text { Drop } \\
\text { Height } \\
\text { d (cm) }\end{array}$} & \multicolumn{3}{|c|}{ Cracking Load $P_{c r}$} & \multicolumn{3}{|c|}{ Ultimate Load $P_{u}$} & \multirow{2}{*}{$\mathbf{P}_{\mathrm{cr}} / \mathbf{P}_{\mathrm{u}}$} \\
\hline & $\alpha_{x}$ & $\alpha_{Y}=b / L$ & & ton & $\operatorname{ton} / \mathrm{m}^{2}$ & $\% \mathbf{S}_{\mathbf{o}}$ & ton & $\operatorname{ton} / \mathrm{m}^{2}$ & $\% S_{0}$ & \\
\hline So & 0.000 & 0.000 & 0.00 & 2.60 & 664 & 1.00 & 6.30 & 4.032 & 1.00 & 0.41 \\
\hline $\mathrm{S}(\mathrm{M}-\mathrm{M} 1 \mathrm{I})$ & 0.1 & & 5.00 & 2.30 & 1.472 & 0.88 & 5.72 & 3.661 & 0.91 & 0.40 \\
\hline $\mathrm{S}(\mathrm{M}-\mathrm{M} 12)$ & 0.250 & 0250 & & 2.60 & 1.664 & 1.00 & 6.30 & 4.032 & 1.00 & 0.41 \\
\hline $\mathrm{S}(\mathrm{M}-\mathrm{M} 13)$ & $\overline{0}$ & 0 & 5 & 2.85 & 1.824 & 1.10 & 7.43 & 4.755 & 1.18 & 0.38 \\
\hline $\mathrm{S}(\mathrm{M}-\mathrm{M} 21)$ & 5 & 5 & & 2.30 & 1.472 & 0.88 & 5.72 & 3.661 & 0.91 & 0.40 \\
\hline $\mathrm{S}(\mathrm{M}-\mathrm{M} 22)$ & 0 & & 7.50 & 2.75 & 1.760 & 1.06 & 6.85 & 4.384 & 1.09 & 0.40 \\
\hline$S(M-M 23)$ & 0 & & 7.50 & 3.20 & 2.048 & 1.23 & 7.80 & 4.992 & 1.24 & 0.41 \\
\hline$S(M$ & & & 10 & 2.50 & 1.600 & 0.96 & 6.30 & 4.032 & 1.00 & 0.40 \\
\hline $\mathrm{S}(\mathrm{N}$ & & .250 & 10 & 2.70 & 1.728 & 1.04 & 6.85 & 4.384 & 1.09 & 0.39 \\
\hline $\mathrm{S}(\mathrm{N}$ & 0 & 0.500 & 10.0 & 3.40 & 2.176 & 1.31 & 8.00 & 5.120 & 1.27 & 0.43 \\
\hline & & 0.250 & 7.50 & 2.60 & 1.664 & 1.00 & 6.30 & 4.032 & 1.00 & 0.41 \\
\hline $\mathrm{S}$ & 0 & 375 & 7.50 & 2.70 & 1.728 & 1.04 & 6.85 & 4.384 & 1.09 & 0.39 \\
\hline & & & 7.50 & 2.75 & 1.760 & 1.06 & 6.85 & 4.384 & 1.09 & $0 . \overline{40}$ \\
\hline & & & 7.50 & 2.60 & 1.664 & 1.00 & 6.30 & 4.032 & 1.00 & $0 . \overline{41}$ \\
\hline & & & 7.50 & 2.60 & 1.664 & 1.00 & 6.30 & 4.032 & 1.10 & 0.41 \\
\hline $\mathrm{S}(\mathrm{C}-\mathrm{C} 3)$ & 0.250 & 0.250 & 7.50 & 2.75 & 1.760 & 1.06 & 7.00 & 4.480 & 1.11 & 0.39 \\
\hline
\end{tabular}

Table 5 Deflections of Various Plate Specimens at Different Loading Stages

\begin{tabular}{|c|c|c|c|c|c|c|c|c|}
\hline \multirow{3}{*}{ Model } & \multicolumn{4}{|c|}{ Deflection Before Cracking ( at 1.714 ton) } & \multicolumn{4}{|c|}{ Deflection After Cracking (at 4.571 ton) } \\
\hline & \multicolumn{2}{|c|}{ Deflection } & \multicolumn{2}{|c|}{ Deflection Factor } & \multicolumn{2}{|c|}{ Deflection } & \multicolumn{2}{|c|}{ Defiection Factor } \\
\hline & $\overline{\mathbf{P 1}}$ & $\mathbf{P 2}$ & $\mathbf{P 1}$ & $\mathbf{P 2}$ & $\mathbf{P 1}$ & $\mathbf{P 2}$ & $\mathbf{P 1}$ & $\mathbf{P 2}$ \\
\hline So & 28 & 1) & 100 & 100 & 66 & 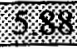 & 100 & 100 \\
\hline S(M-M11) & 3.77 & 2.48 & 1.16 & 1.18 & 9.24 & 6.30 & 1.05 & 1.07 \\
\hline$S(M-M 12)$ & 3.13 & 2.10 & 0.96 & 0.99 & 8.52 & 5.82 & 0.97 & 0.99 \\
\hline $\mathrm{S}(\mathrm{M}-\mathrm{M} 13)$ & 2.14 & 1.69 & 0.66 & 0.80 & 6.00 & 4.80 & 0.68 & 0.81 \\
\hline $\mathrm{S}(\mathrm{M}-\mathrm{M} 21)$ & 3.54 & 2.40 & 1.09 & 1.13 & 9.12 & 6.12 & 1.04 & 1.04 \\
\hline $\mathrm{S}(\mathrm{M}-\mathrm{M} 22)$ & 3.01 & 2.03 & 0.93 & 0.96 & 8.22 & 5.80 & 0.94 & 0.99 \\
\hline $\mathrm{S}(\mathrm{M}-\mathrm{M} 23)$ & 1.94 & 1.66 & 0.60 & 0.78 & 5.58 & 4.68 & 0.64 & 0.80 \\
\hline $\mathrm{S}(\mathrm{M}-\mathrm{M} 31)$ & 3.30 & 2.21 & 1.02 & 1.05 & 8.94 & 6.00 & 1.02 & 1.02 \\
\hline $\mathrm{S}(\mathrm{M}-\mathrm{M} 32)$ & 2.95 & 1.94 & 0.91 & 0.92 & 8.10 & 5.64 & 0.92 & 0.96 \\
\hline $\mathrm{S}(\mathrm{M}-\mathrm{M} 33)$ & 1.90 & 1.63 & 0.59 & 0.77 & 5.34 & 4.66 & 0.61 & 0.79 \\
\hline $\mathrm{S}(\mathrm{M}-\mathrm{Cl})$ & 3.18 & 1.99 & 0.98 & 0.94 & 8.58 & 5.34 & 0.98 & 0.91 \\
\hline $\mathrm{S}(\mathrm{M}-\mathrm{C} 2)$ & 3.01 & 1.58 & 0.93 & 0.75 & 8.08 & 4.32 & 0.91 & 0.73 \\
\hline $\mathrm{S}(\mathrm{M}-\mathrm{C} 3)$ & 2.82 & 1.15 & 0.87 & 0.55 & 7.68 & 3.30 & 0.88 & 0.56 \\
\hline S (C-C1) & 3.28 & 2.06 & 1.01 & 0.98 & 8.88 & 5.76 & 1.01 & 0.98 \\
\hline $\mathrm{S}(\mathrm{C}-\mathrm{C} 2)$ & 3.24 & 1.98 & 1.00 & 0.94 & 8.28 & 5.52 & 1.00 & 0.94 \\
\hline $\mathrm{S}(\mathrm{C}-\mathrm{C} 3)$ & 2.66 & 1.61 & 0.79 & 0.76 & 7.08 & 4.56 & 0.81 & 0.78 \\
\hline
\end{tabular}



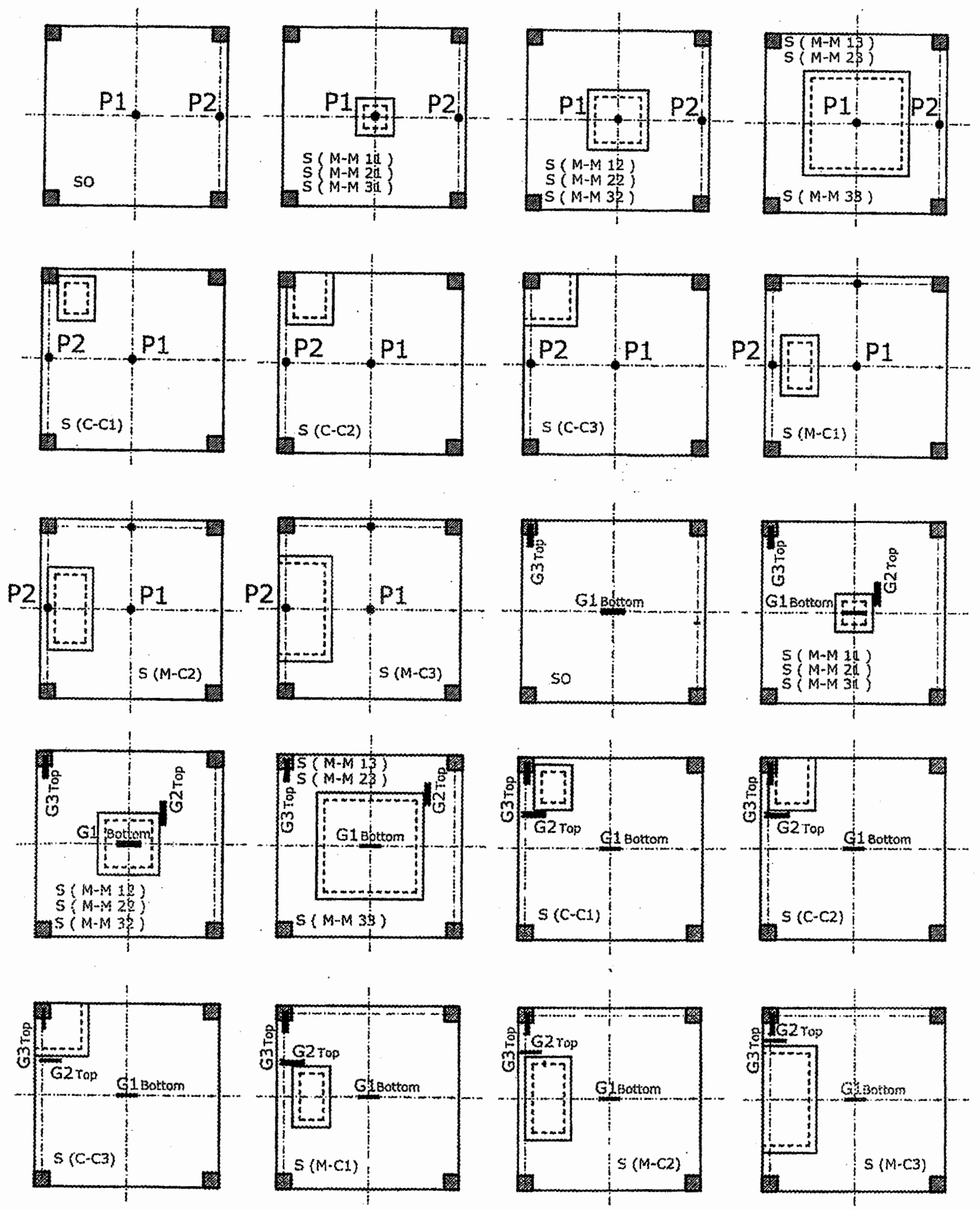

Fig. 1 Location of Drop Parts, Dial Gauges and Electrical Strain Gauges on the Reinforcement of Various Plate Specimens 
Mohamed H. Matthana, Attia H. Bayomy,A.H. Abdel-Reheem,Ayman Mashaly, " Experimental Study ... "
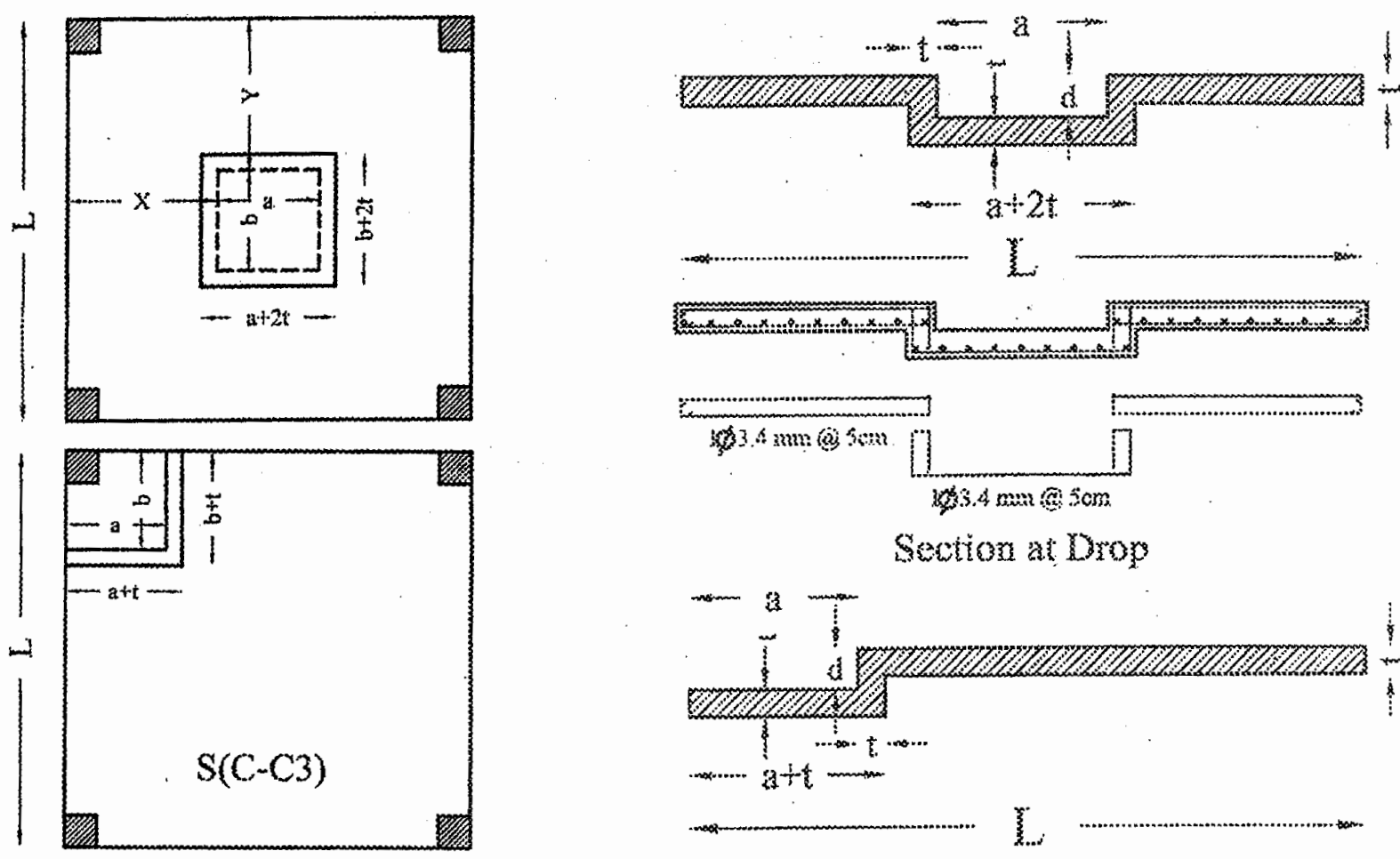

L

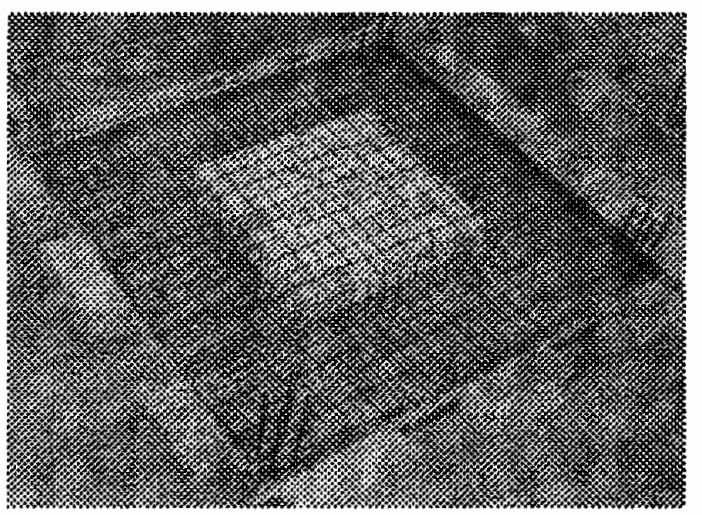

Sewronat aroy
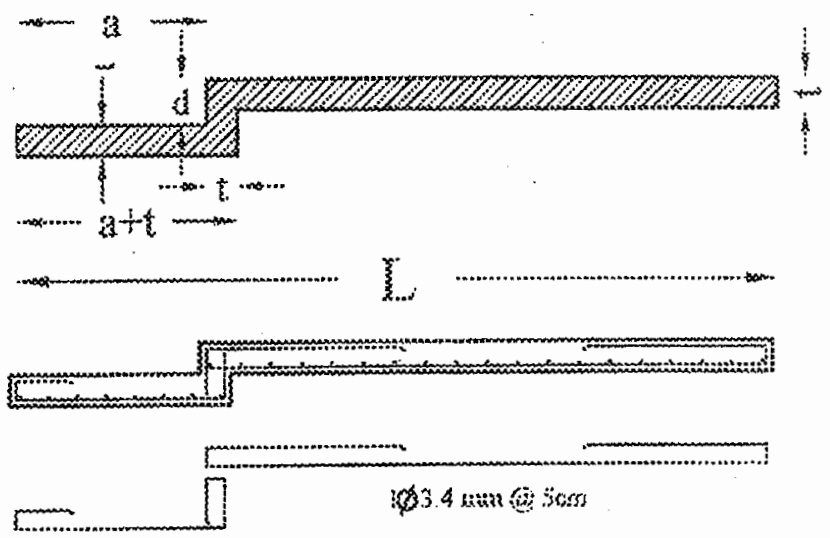

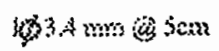

Section as Drop

|C:

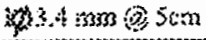

Soction in plate

Fig. 2 Configurations of Plate Specimens

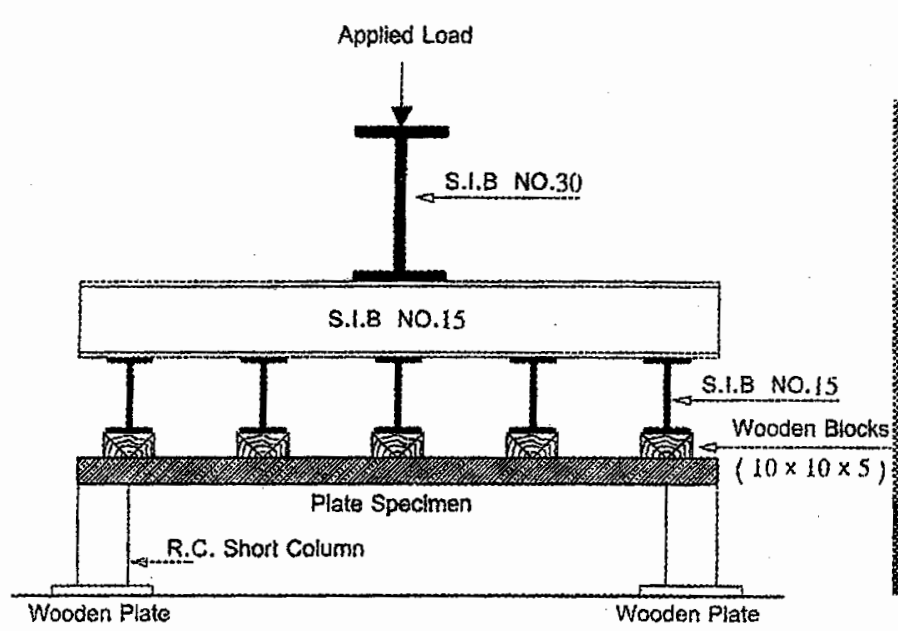

Fig. 3 Experimental Test Set Up

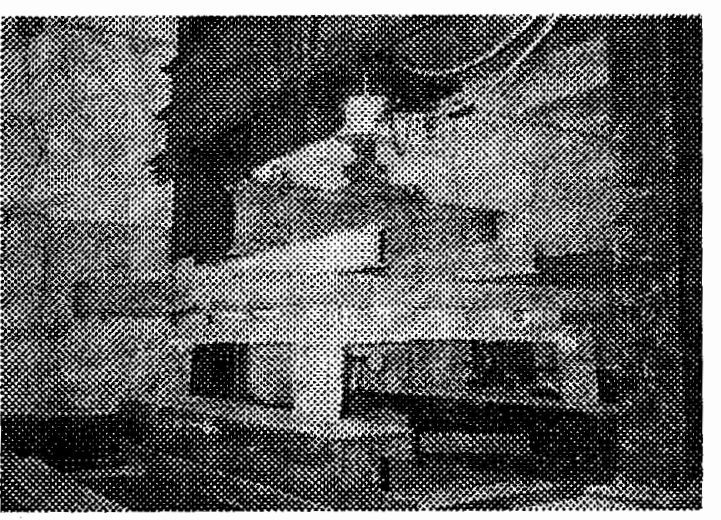

Plate (1) Experimental Test Set Up 







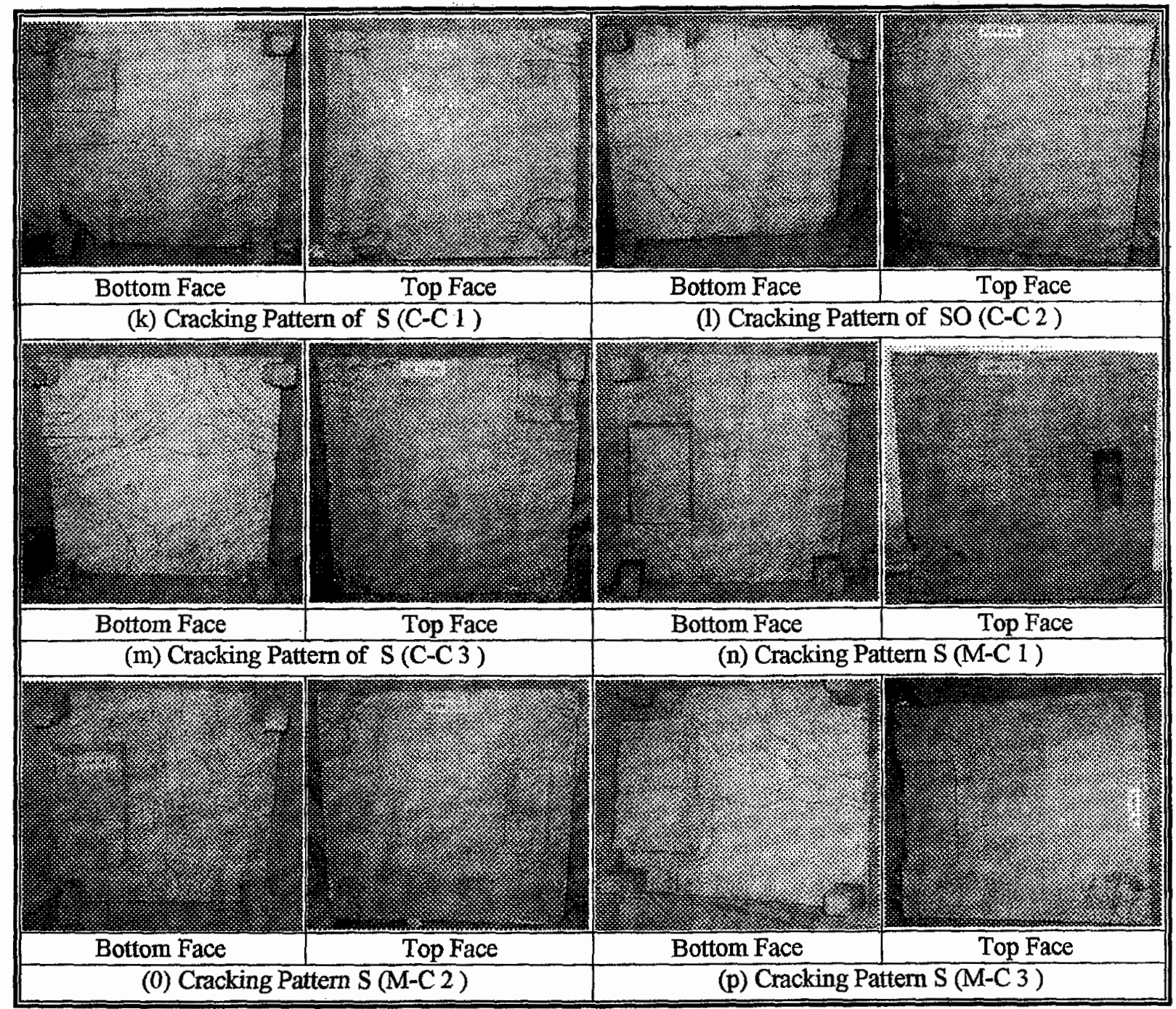

Plate ( 2 ) Cracking Patterns of Various Groups of Plate Specimens

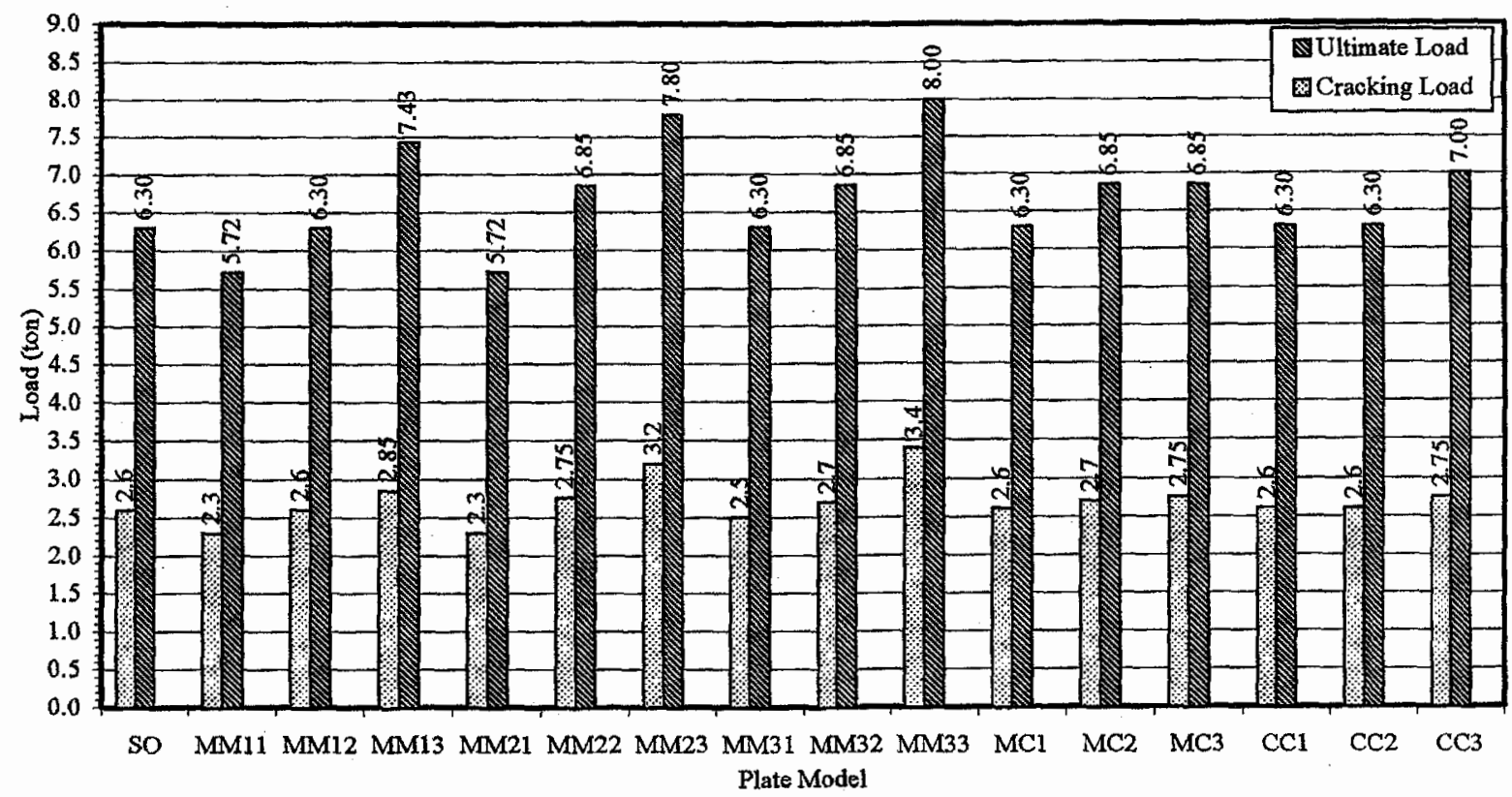

Fig. 4 Variation in Both Cracking and Ultimate Loads of Various Plate Specimens 


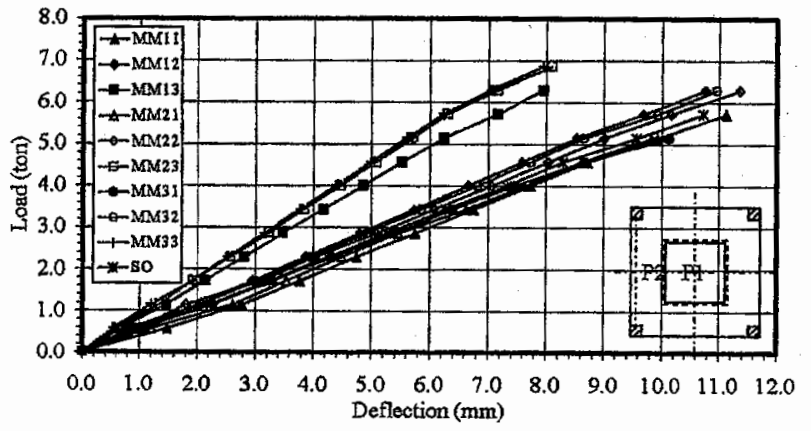

Fig. 5 Load-Deflection Relationship of M-M Group at Point P1

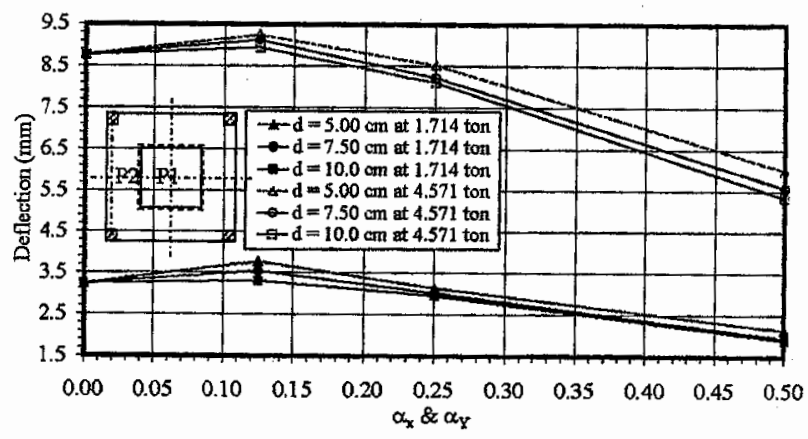

Fig. 7 Relationship Between Deflection and Drop Ratio for M-M Group at P1

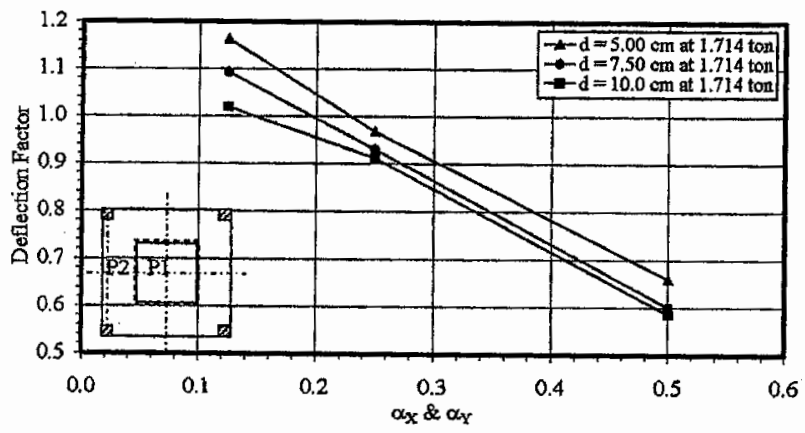

Fig. 9 Relationship Between Deflection Factor and Drop Ratio for M-M Group at P1 (Before Cracking)

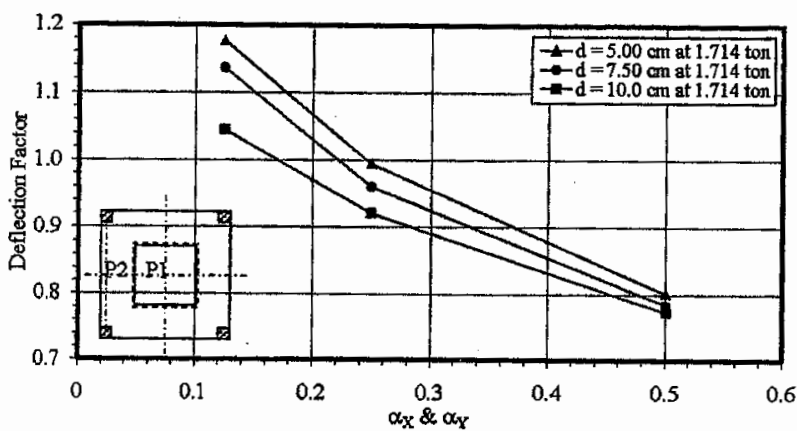

Fig. 11 Relationship Between Deflection Factor and Drop Ratio for M-M Group at P2 (Before Cracking)

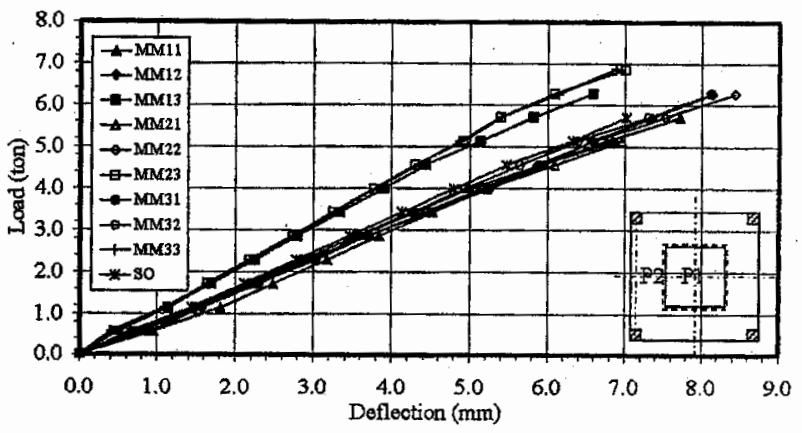

Fig. 6 Load-Deflection Relationship of M-M Group at Point P2

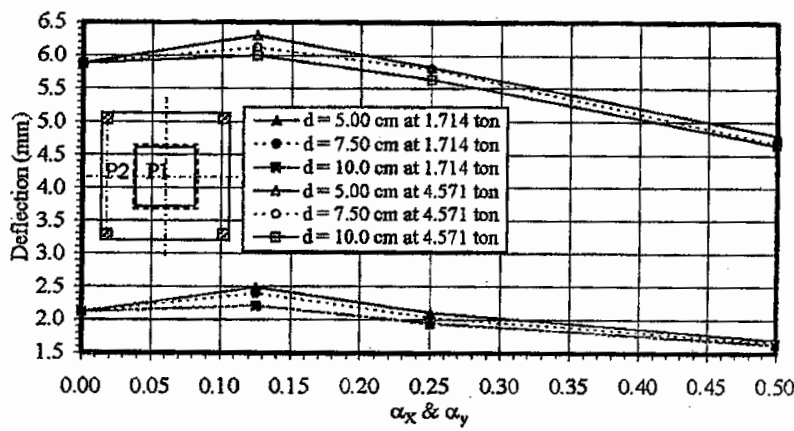

Fig. 8 Relationship Between Deflection and Drop Ratio for M-M Group at P2

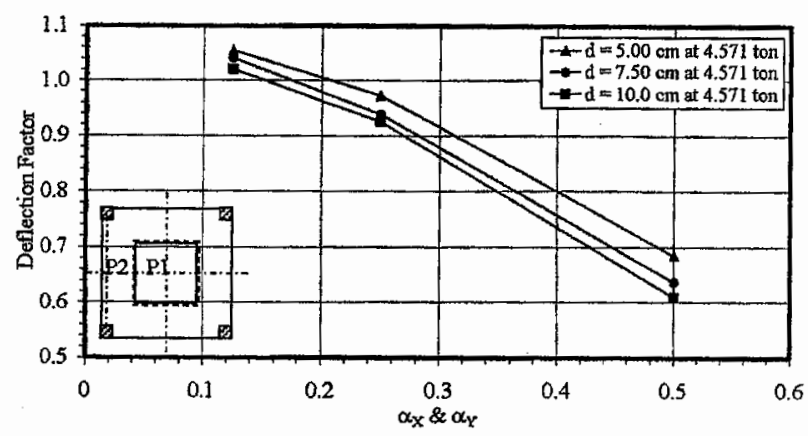

Fig. 10 Relationship Between Deflection Factor and Drop Ratio for M-M Group at P1 (After Cracking)

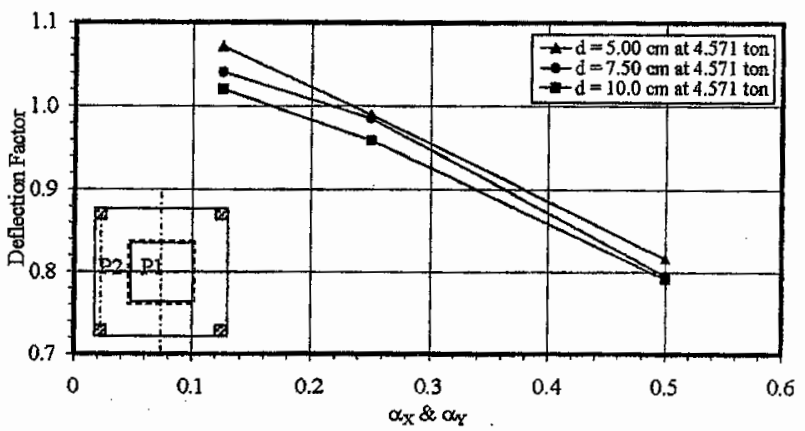

Fig. 12 Relationship Between Deflection Factor and Drop Ratio for M-M Group at P2 (After Cracking) 


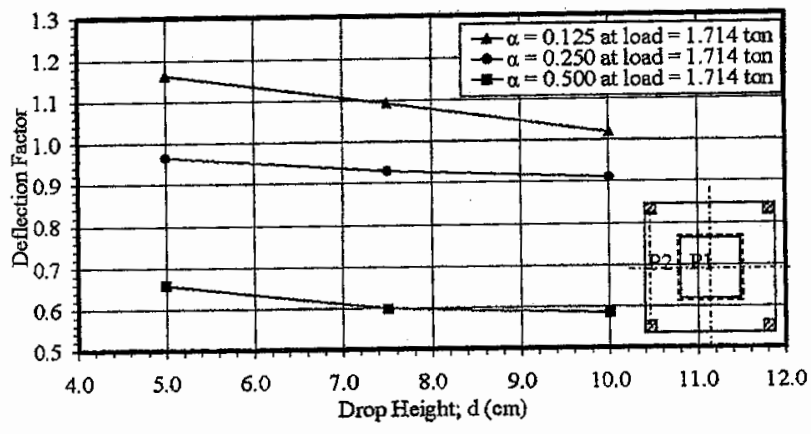

Fig. 13 Relationship Between Deflection Factor and Drop Height for M-M Group at P1 (Before Cracking)

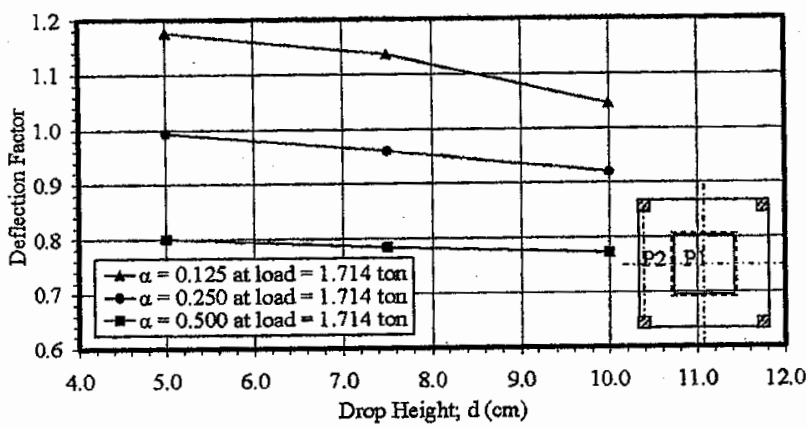

Fig. 15 Relationship Between Deflection Factor and Drop Height for M-M Group at P2 (Before Cracking)

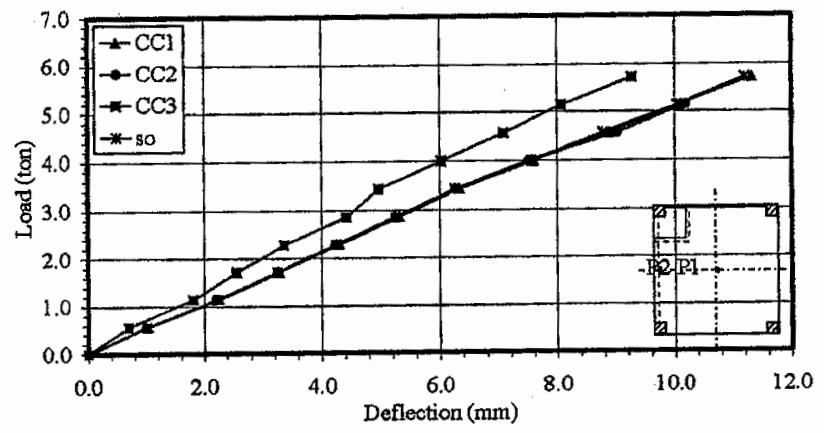

Fig. 17 Load-Deflection Relationship of C-C Group at Point P1

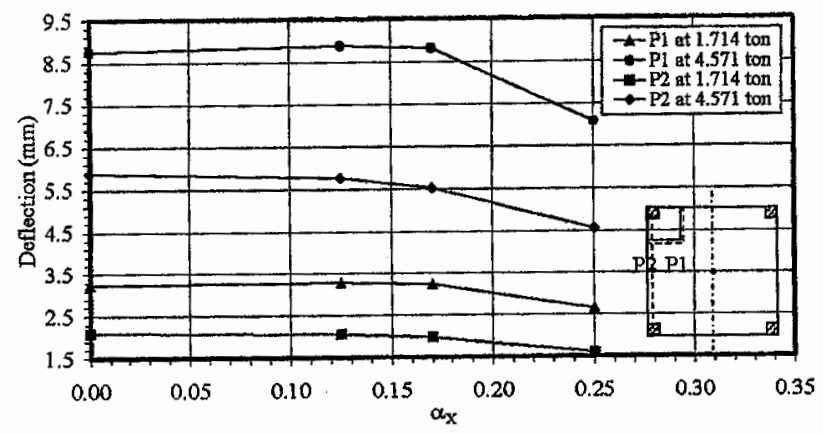

Fig. 19 Relationship Between Deflection and Drop Ratio for C-C Group

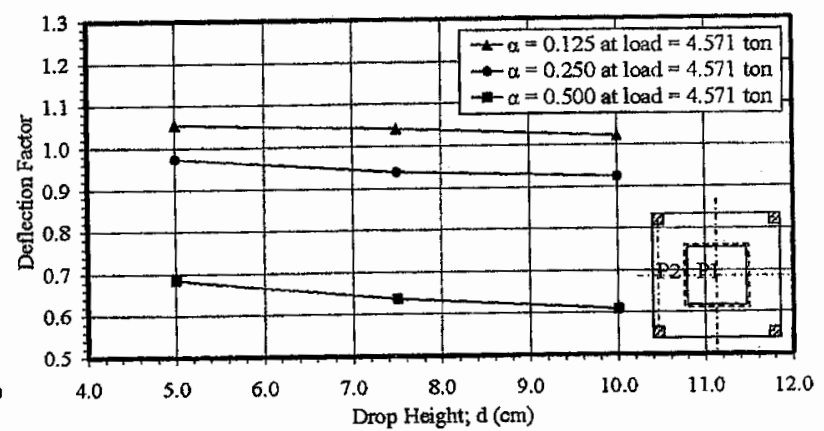

Fig. 14 Relationship Between Deflection Factor and Drop Height for M-M Group at P1 (After Cracking)

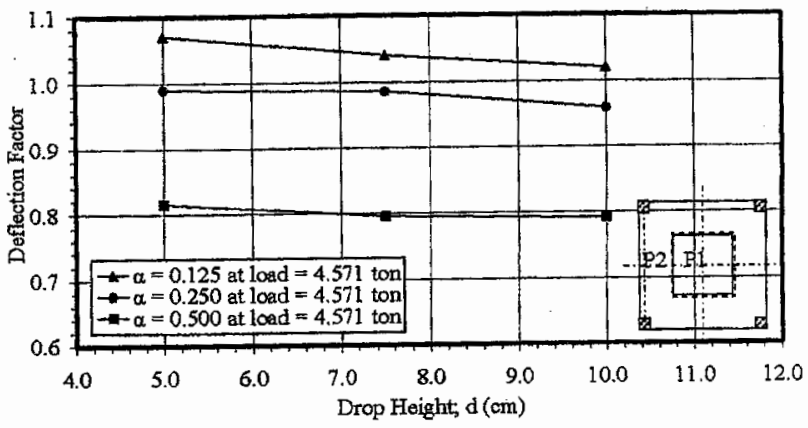

Fig. 16 Relationship Between Deflection Factor and Drop Height for M-M Group at P2

(After Cracking)

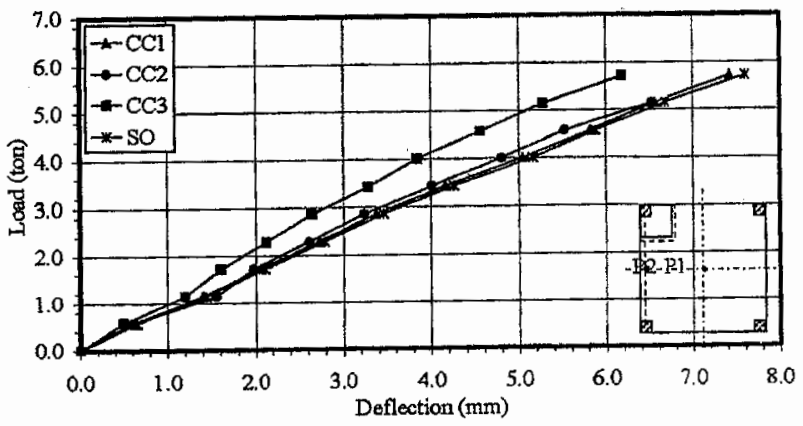

Fig. 18 Load-Deflection Relationship of C-C Group at Point P2

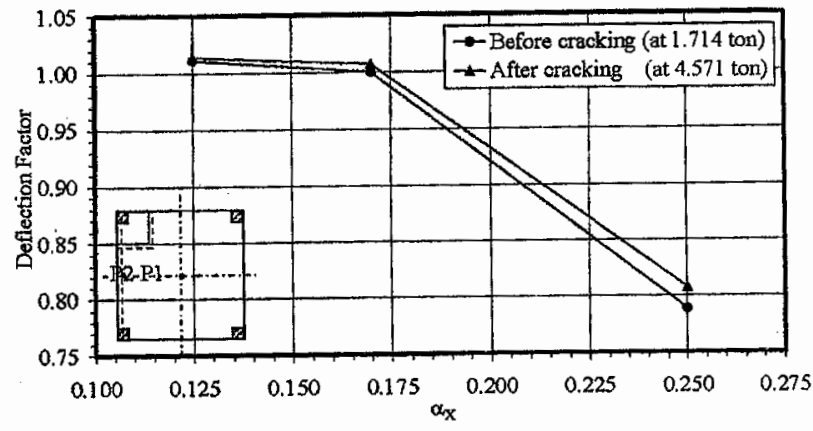

Fig. 20 Relationship Between Deflection Factor and Drop Ratio for C-C Group at P1 


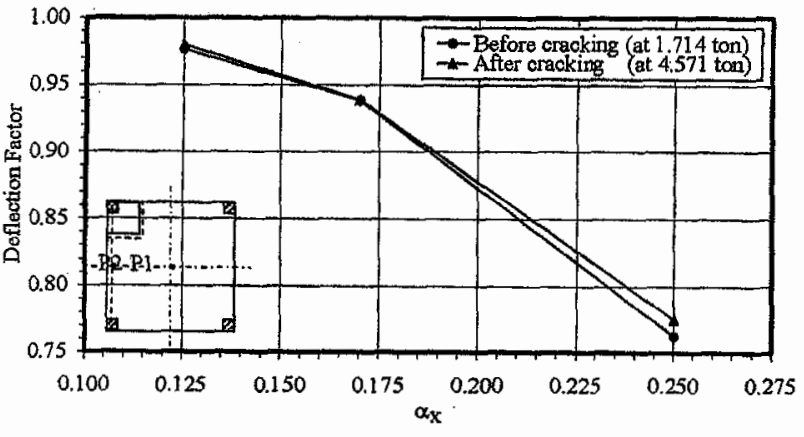

Fig. 21 Relationship Between Deflection Factor and Drop Ratio for C-C Group at P2

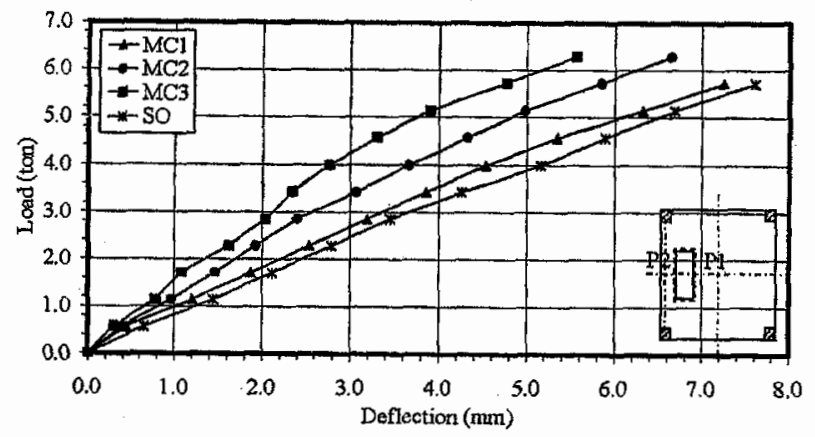

Fig. 23 Load-Deflection Relationship of M-C Group at Point P2

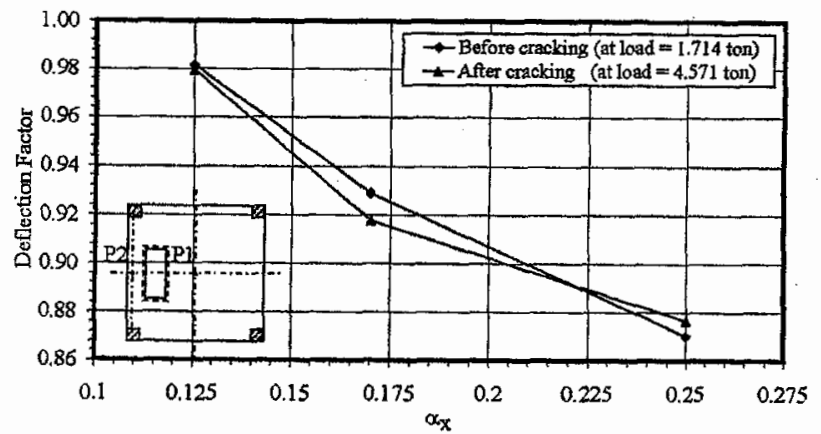

Fig. 25 Relationship Between Deflection Factor and Drop Ratio for M-C Group at P1

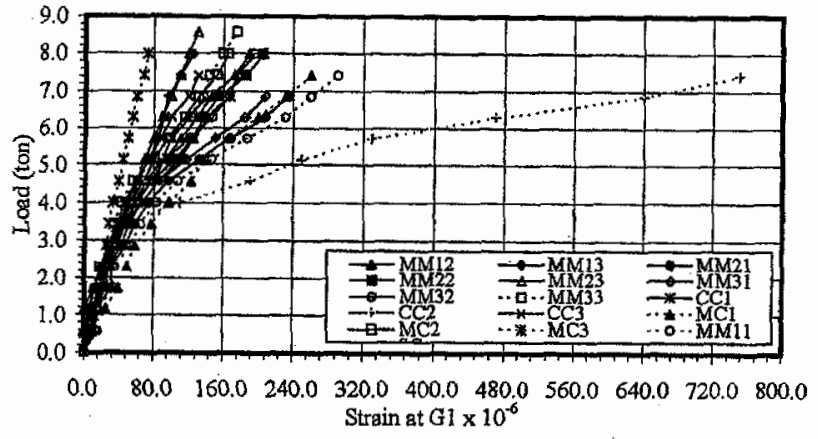

Fig. 27 Variation in Steel Strains with the Applied Load at Point GI

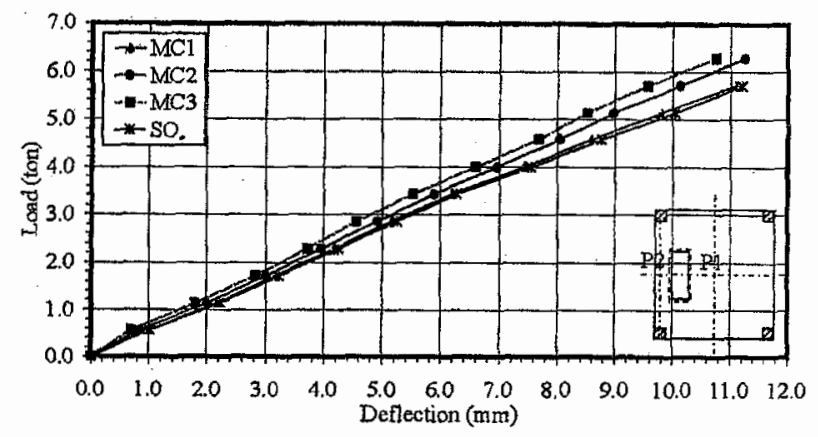

Fig. 22 Load-Deflection Relationship of M-C Group at Point P1

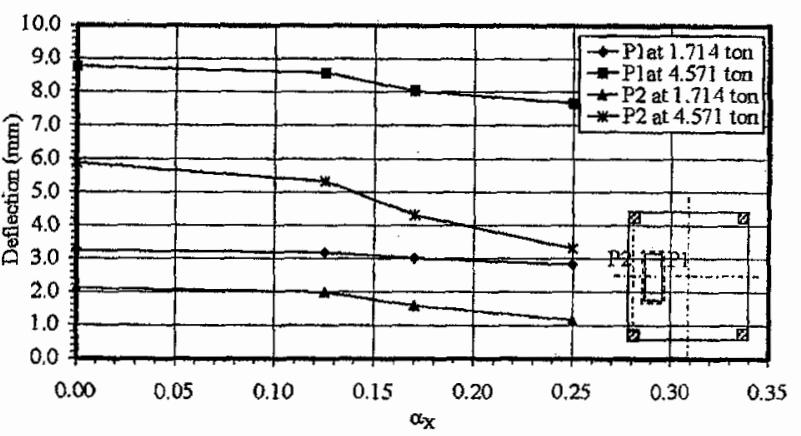

Fig. 24 Relationship Between Deflection and Drop Ratio for M-C Group

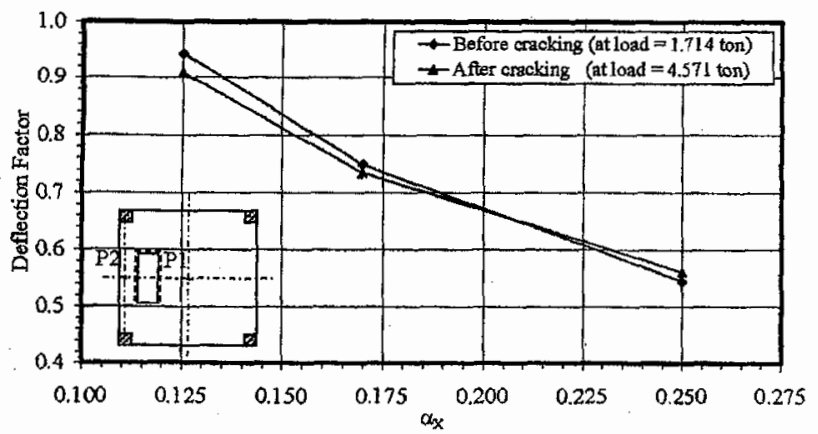

Fig. 26 Relationship Between Deflection Factor and Drop Ratio for M-C Group at P2

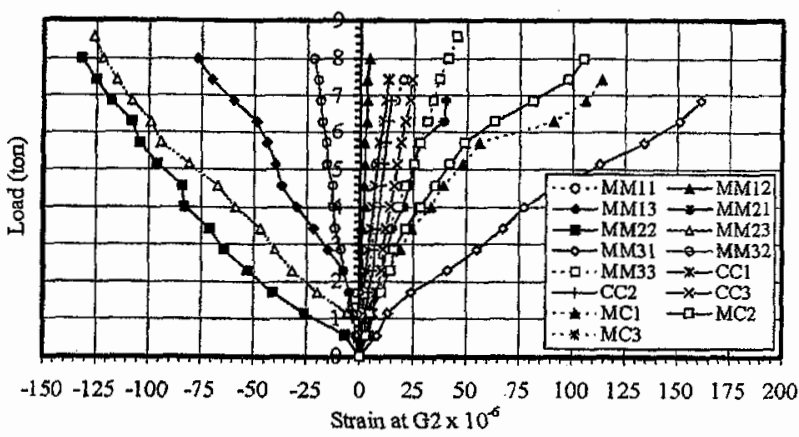

Fig. 28 Variation in Steel Strain with the Applied Load at Point G2 


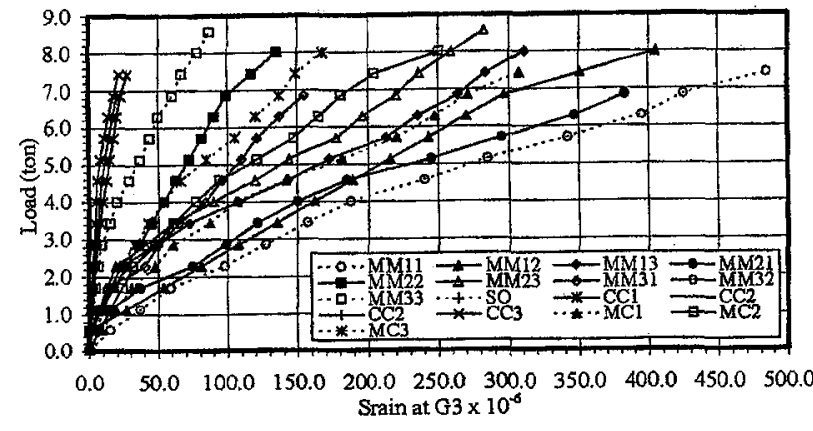

Fig. 29 Variation in Steel Strain with the Applied Load at Point G3

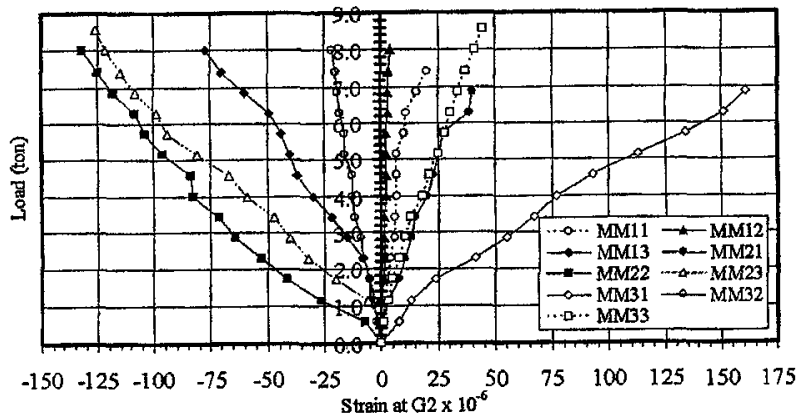

Fig. 31 Variation in Steel Strains with the Applied Load for M-M Group at G2

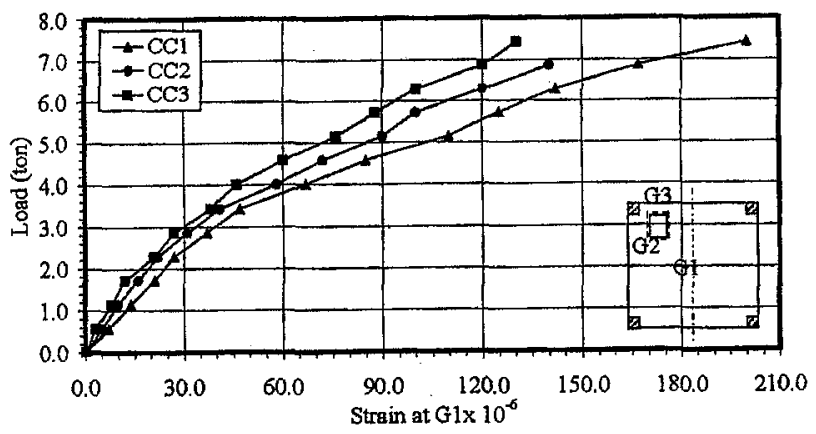

Fig. 33 Variation in Steel Strains with the Applied Load for C-C Group at G1

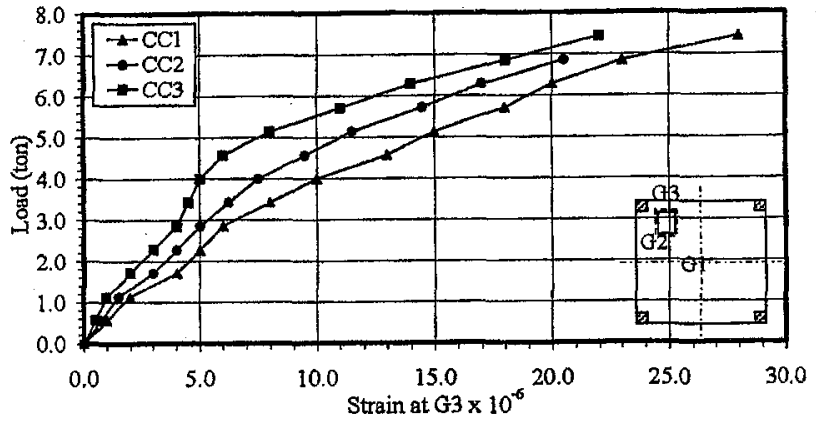

Fig. 35 Variation in Steel Strains with the Applied Load for C-C Group at G3

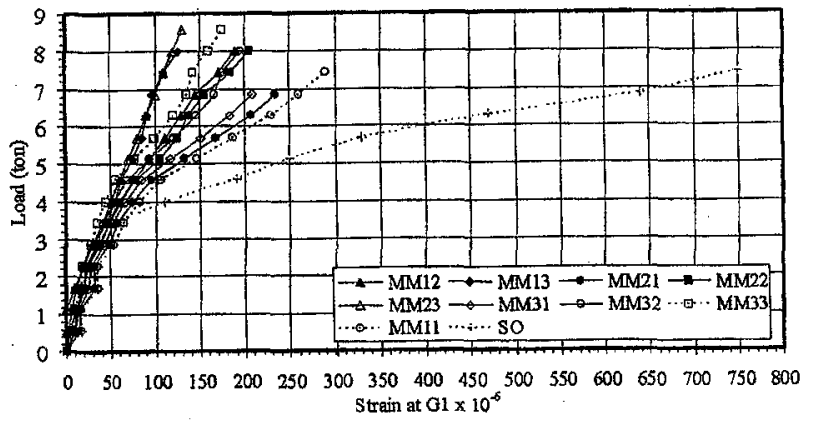

Fig. 30 Variation in Steel Strains with the Applied Load for M-M Group at G1

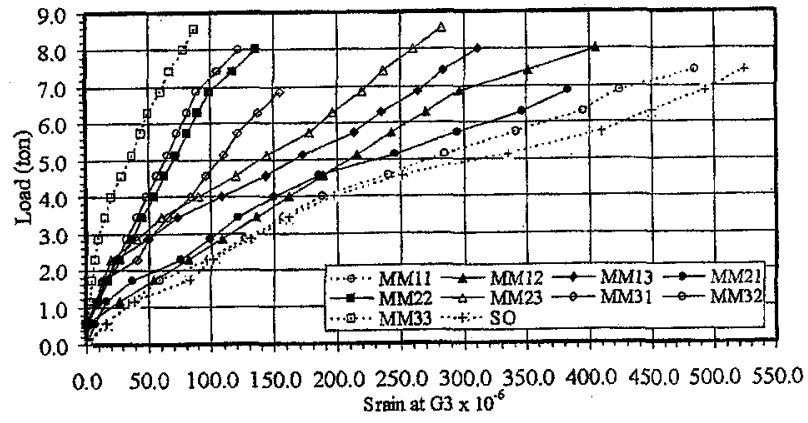

Fig. 32 Variation in Steel Strains with the Applied Load for M-M Group at G3

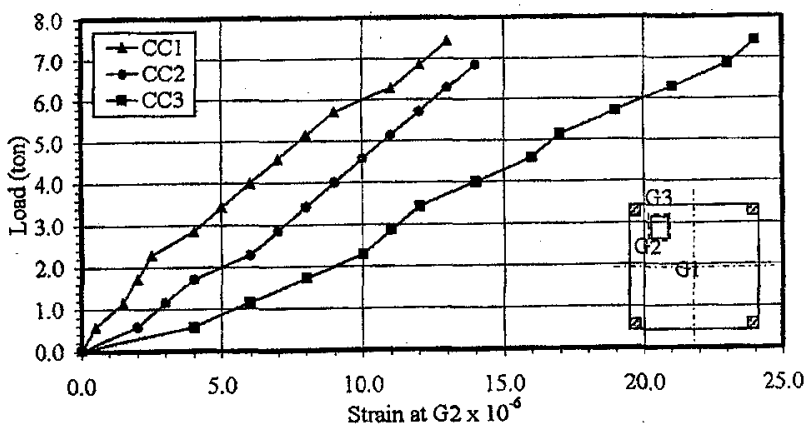

Fig. 34 Variation in Steel Strains with the Applied Load for C-C Group at G2

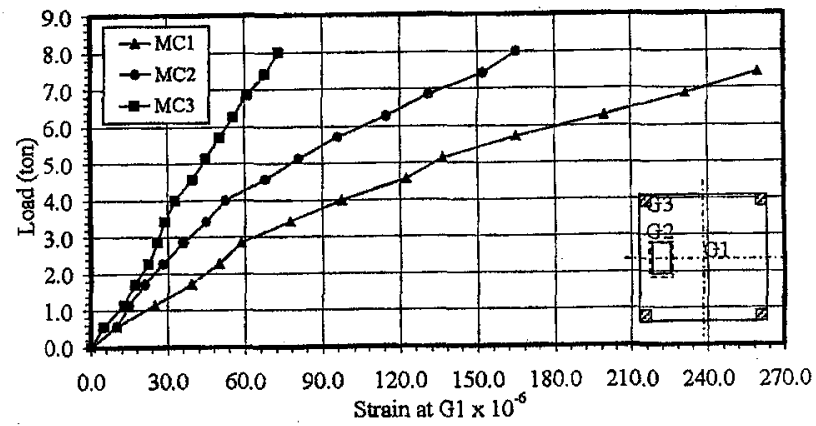

Fig. 36 Variation in Steel Strains with the Applied Load for M-C Group at G1 


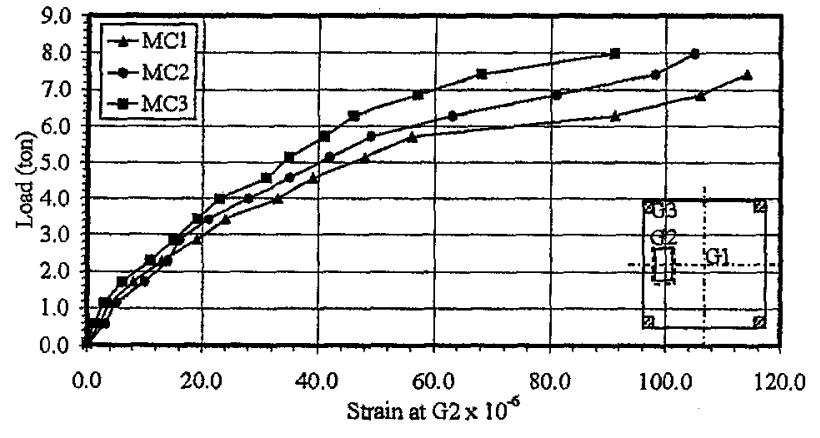

Fig. 37 Variation in Steel Strains with the Applied Load for M-C Group at G2

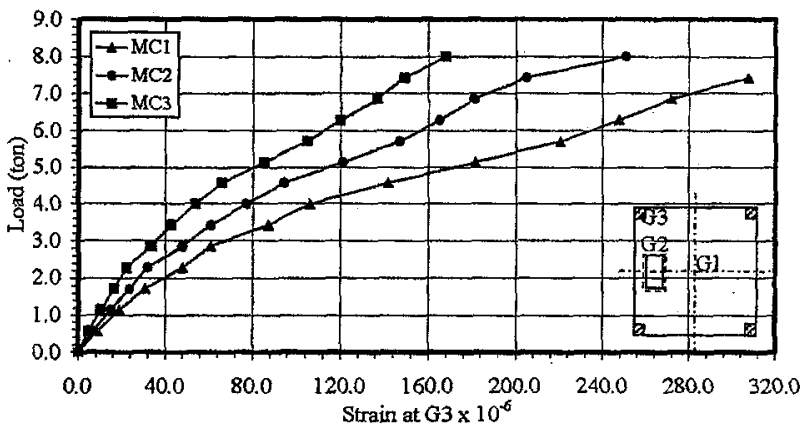

Fig. 38 Variation in Steel Strains with the Applied Load for M-C Group at G3 